\title{
V/STOL Aircraft Configurations and Opportunities in the Pacific Basin
}

James A. Albers and John Zuk

Ames Research Center, Moffett Field, California

August 1987

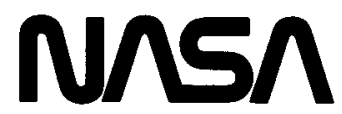

National Aeronautics and

Space Administration

Ames Research Center

Moffett Field. California 94035 


\section{ABSTRACT}

Advanced aircraft configurations offer new transportation options for the Pacific Basin. This paper describes a range of vehicles from low-disk to high-disk loading aircraft, includ-

- ing high-speed rotorcraft, subsonic vertical and short takeoff and landing (V/STOL) aircraft, and subsonic short takeoff and landing (STOL) aircraft. The status and advantages of the various configurations are described. Some of these configurations show promise for satisfying many of the transportation requirements of the Pacific Basin; as such, they could revolutionize short-haul transportation in that region.

WORLDWIDE, INCLUDING THE ASIAN-PACIFIC REGION, there is a strong desire to improve each nation's economy and quality of $11 \mathrm{fe}$. Future world population growth, along with developing countries' desires to become highly industrialized, requires efficient transportation system. As always, it will be highly desirable to transport people and high-value cargo as rapidly and as economically as possible. Many regions of the world lack suitable ground transportation systems and have formidable geographic barriers. In urban developed areas, both ground congestion and air congestion around existing airports will become severe. In most areas it is difficult, if not impossible, to expand airports, particularly because of the congestion and noise.

Fortunately, there is a solution to these transportation problems--V/STOL aircraft. Technology advances in materials, propulsion, aerodynamics, controls, guidance, and the integration of these technologies are ylelding many promising designs that show the potential for revolutionizing short-haul transportation.
Promising designs, including the state of development of the configurations, are described. The full range of vehicles from lowdisk-loading advanced hellcopters to high-diskloading direct lift aircraft are discussed, including high-speed rotorcraft, subsonic V/STOL aircraft, and subsonic STOL aircraft. Future transportation opportunities, along with VTOL and STOL transportation systems, are described. The various configurations are compared and their advantages are highlighted. This report indicates that these aircraft can satisfy many of the transportation requirements of the Pacific Basin, and that they could be of a great benefit to that region.

GEOGRAPHY AND TRANSPORTATION REQUIREMENTS OF THE ASIAN PACIFIC REGION

The economic growth rates of the Asian Paciflc Rim countries are leading the world (from $4.7 \%$ to $9 \%$ per year). This growth rate has been accompanied by heightened emphas is on trade. In 1984, the U.S. trans-Pacific trade was $33 \%$ of the U.S. total--larger than all of the U.S.-European trade. In the future, continued growth is anticipated since the region has $60 \%$ of the world's population and the world's three largest economies (1)*. The increase in U.S. trans-Pacific trade is reflected in large projected passenger traffic growth from 1985-2000 (Fig. 1). The largest

Numbers in parentheses designate references at end of paper. 
growth projection is shown to be a $370 \%$ increase in revenue passenger miles between the United States and the Pacific Basin. This projection is a driver for the "Orient Express," a proposed hypersonic cruise airliner that would reduce travel time from the United States to anywhere in the Pacific Basin to less than $3 \mathrm{hr}$. The implications of this vehicle would undoubtedly result in an even further increase in trade and commerce (2).

The region is enormous, encompassing two continents, more than one half of the world's islands, the largest of the world's oceans, and almost every type of terrain and climate (Fig. 2). Collectively, the islands comprise somewhat more than 600,000 square miles, but those islands are set in a sea area of more than 34 million square miles. The north-to-south distance from the Bering Strait to the Antarctic Circle is about 9,300 miles. The Pacific Basin also includes some of Earth's most densely populated areas (e.g., Tokyo--the world's largest city), as well as vast uninhabited areas. As with most developing regions of the world, there are many resources and marketing assets that are coupled with a strong desire to improve the economic well-being and quality of iffe. In most cases, the fulfillment of this desire involves solving a transportation problem.

Several Pacific Basin region areas will now be examined to identify some of the geographic and economic transportation requirements that provide V/STOL transportation opportunities, beginning with the lower-population density areas.

INDONESIA - Indonesia is a archipelago consisting of 13,667 islands, most of which are uninhabited. Only the major islands, particularly Java, have been developed to any large extent, and only Java and Sumatra have reasonably well-developed transport systems (3). Freight movements are dependent on sea transport, with major population centers close to the sea. Rail is restricted to short distances, and internal roadways are poorly developed. On remote islands, where future development may occur owing to discovery of resources, transport facilities may be almost nonexistent. Typically, roads are few and difficult to maintain in good condition; rivers, where they exist, are useful mostly for floating logs; and airfields cleared for World War II use have been reclaimed by the jungle. In 1986, Indonesia had 393 usable airports; 95 of those were paved, and only 12 had long-haul conventional takeoff and landing (CTOL) runways.
Alr transport plays a vital role in Indonesia in promoting national cohesiveness which is difficult to achieve because of the long distances between the outer islands and the major centers on Java, Bali, and Sumatra. This means that future development of the resources on these islands must rely on air and water transport. Lack of port and inland transport facilities probably dictates use of V/STOL alrcraft because these vehicles require the least ground space.

The existence of known resources in Indonesia is impressive. Future exploration will undoubtedly expand these reserves, since it has been estimated that only $5 \%$ of the country's land area has been systematically explored and mapped in any detail. V/STOL aircraft can replace or supplement existing slow and unreliable surface transport. Since land and ground preparation requirements are minimal for $V / S T O L$ aircraft, they appear to offer a great opportunity.

OCEANIA - Oceania comprises over 25,000 islands spread over a large area of the Pacific ocean. Representative island groups within this region are shown in Fig. 3. The large islands of Melanesia are characterized by extremely rugged interior mountain ranges, divided plateaus, and precipitous interior valleys. Lower and coastal areas tend to be divided by twisting rivers, alternating swampy areas of coastal plains, or narrow coastal shelves. Significantly, the topography creates barriers that function to keep human populations separated and divided into small linguistic and political comunities. Since many islands are located in the equatorial belt, many islands will have tourism as a major growth industry. V/STOL aircraft offers rapid and reliable air passenger service opportunities. Similar transportation requirements exist for development of export markets for high-value, perishable, and nonperishable agricultural products and other goods. AUSTRALIA - Australia is a continent about the same size as the continental United States, but with a much smaller population--less than 16 million. Since two-thirds of the population inhabits only five major coastal cities and most of the remainder lives in smaller cities and towns along the temperate eastern coastal fringe, the vast arid interior is very sparsely populated. The few large settlements in the tropical north are separated by great distances and linked, if at all, by roads that the wet season regularly renders impassable.

Principal V/STOL application areas include mining support, tourism, and commuting. There is also the potential of the using V/STOLs to 
replace conventional hellcopters supporting of fhore mining operations because of improved speed and range of V/STOL alrcraft. Also, there is the further possibility of their replacing the small CTOL transports serving inland mining operations. Many tourism route opportunities have been identified such as: Brisbane to the Barrier Reef islands; Allce Springs to Ayers Rock; and Sydney, Melbourne, and Canberra to the Snowy Mountains. Commuter airline candidates have also been identified. V/STOL aircraft could be used for such routes to major cities such as Sydney-Canberra, Melbourne-Canberra, and Melbourne-Sydney assuming central airport facilities (4).

JAPAN - Japan is geographically characterized by its mountainous districts and its many islands. Since Japan is an insular and mountainous country, it lends itself to air transportation. Over $30 \mathrm{milli}$ ion passengers are transported annually on the domestic routes. Table 1 indicates the magnitude of scheduled air service on major domestic routes. Major population concentrations are located on various islands, and the distances between those population centers, with Tokyo fairly centrally located from a north-south standpoint, are relatively short. The markets are among the most dense in the world and land is at a premium, especially in urban areas. High-density air traffic and high land costs are favorable for future V/STOL aircraft service. Also, Japan's major airports have ground congestion problems that could be relieved by V/STOL aircraft service to many locations.

The above described geographical areas are representative of the Pacific Basin and indicate the variety of the region's transportation requirements and the many opportunities it holds for V/STOL aireraft.

\section{V/STOL TRANSPORTATION OPPORTUNITIES}

$V /$ STOL aircraft have great potential as economic tools for developing regions and can provide congestion relief for existing airports and densely populated areas. First, future transportation opportunities for developing countries and regions will be briefly discussed. LOW POPULATION DENSITY REGION - Future V/STOL aircraft economic development opportunities include passenger service, agriculture products, emergency services, mineral development transport, law enforcement, fishing, and high-value cargoes. V/STOL aircraft should be suited as a passenger and high-value-cargo transport for areas that lack ground transportation systems which are expensive to build or maintain. Undeveloped natural resources are 3 characteristic of some remote regions. Another characteristic is the relatively short and umimproved existing airport runways. Jentures that seem particularly suited for such aircraft include mining industries, such as copper and aluminum; petroleum exploration; associated wood products; high-value-added manufacturing; and agricultural products. Helicopters have virtually monopolized servicing of offshore oil rigs because they are more productive shan ships. Projecting to the next century, oil rigs can be expected to be located farther offshore and, in general, other resources such as minerals are expected to be extracted from more difficult geographic locations as more readily accessible sources are depleted. Other new opportunities may exist, such as ocean mining, that may offer other opportunities for the application of long-range, vertical takeoff and landing aircraft. $\mathrm{V} / \mathrm{STOL}$ and STOL air transportation may offer a solution for special seasonal needs for industries such as the fisheries. Rapid transport of fish from various Pacific islands to canneries is required during highyield seasons. Also, the basic health and welfare needs of citizens located in remote and isolated areas could be served by V/STOL aircraft. Generally, remote area service requires small aircraft, another point in favor of V/STOLs.

HIGH POPULATION DENSITY REGIONS - As energy, land, and congestion constraints reduce the advantages of the automobile, intercity air transportation will increase in importance, primarily because of the importance of time to the traveler and the growing efficiency, flexibility, reliability, and wider distribution of air transportation services. The addition of new, large, and conveniently located airports will be increasingly constrained by environmental, ground access, and economic factors. Making better use of existing transportation hubs, secondary and small community airports will become increasingly more important to avoid serious air transportation congestion and business and economic stagnation. In the future, even with the use of advanced air traffic control technology and wide-body aircraft technology, runway capacity limits will have been reached in many of the major hub airports.

To reduce the negative results of such saturation, communities will consider more effective use of available hub and secondary airports, and the use of V/STOL aircraft offers a high payoff transportation opportunity. $V /$ STOL aircraft terminal flight-path control capability will allow the use of helicopter 
terminal-area flight rules so that they will pose no additional burden to crowed airports. Significant airport rellef can be obtained through the use of these vehicles when they do not use existing airports, but instead carry passengers almost point-to-point using vertiports. Figure 4 illustrates potential V/STOL aircraft landing facilities. These include seaports along rivers or lakes that also use existing piers or barges, facilities located adjacent to or above other existing transportation modes, such as railroads, light rail or subways; and highways enabling a highly efficient intermodal transfer. Existing urban and remote heliports can also be used for most V/STOL aircraft. Coupling these facility possibilities with existing general aviation airports means an extensive vertiport groundfacility system could be available. Figure 5 is an artist's rendition of an airport expansion possibility where an airport is saturated with CTOL traffic and is constrained from expanding externally. V/STOL aircraft can provide highfrequency, short- and medium-haul service, operating on vertipads or short runways that generally can be placed on existing airports. The CTOL runways can then be used for the longer-haul, wide-body aircraft. Thus, the airport capability can be greatly increased. In order to satisfy the transportation requirements and opportunities in the Pacific Basin, a broad range of V/STOL aircraft configurations was examined. These are shown as functions of disk loading and airspeed in Fig. 6 . Disk loading (defined as thrust divided by a representative area, e.8., propeller disk, shroud exit, and fet nozzle areas) provides a rational basis for comparing various configurations. The disk loadings of the conflgurations considered in this paper range from 10 to $3,0001 \mathrm{~b} / \mathrm{ft}^{2}$ and cruise airspeeds range from about 200 to 600 knots. These configurations will be discussed in more detail in subsequent sections of this paper.

\section{ADVANCED HIGH-SPEED ROTORCRAFT CONFIGURATIONS}

This section will discuss a range of highspeed (greater than 200 knots) rotorcraft configurations for which applications might exist in the Pacific Basin. The designs discussed include the tilt rotor, folding tilt rotor, compound, and stopped-rotor configurations. A historical perspective of advanced rotorcraft developments in the United States is given in Ref. 5 .

TILT ROTOR - The tilt-rotor aircraft combines the low-disk-loading VTOL capability of a helicopter with standard turboprop aircraft cruise flight. The design has been proved in the XV-15 tilt-rotor research aircraft

(Fig. 7). A unique feature of this aircraft is the two large, three-bladed proprotors mounted at the tips of the wings. For takeoff, the axes of the proprotors and their engines are rotated to the vertical position where the lift developed is entirely propulsive. The XV-15 can climb vertically like a helicopter. The XV-15 has the ability to fly in one of three different modes: as a helicopter, in the partially converted tilt-rotor mode, or in the fully converted airplane mode. The XV-15 converts from the helicopter mode to the airplane mode safely and rapidly by continuously tilting the proprotors from the helicopter rotor position to the conventional airplane propeller position. During the 10- to $15-$ sec conversion period, the aircraft speed increases and lift is transferred from the rotors to the wing. To land, the proprotors are rotated up to the helicopter rotor position and the aircraft is flown as a helicopter to a vertical landing. The ability of the XV-15 to rotate its proprotors to different angles also makes it possible to operate as a STOL aircraft. Proprotor tilt angles of $60^{\circ}-70^{\circ}$ produce lift from both the proprotors and wings. Heavier payloads can be lifted in this STOL mode operation than in helicopter-mode operation.

Two XV-15s were built by Bell Helicopter Textron under a joint NASA-Army contract. One aircraft is engaged in a flight research program at Ames Research Center, the other is being operated by the Bell Helicopter Company in Arlington, Texas, and is being used for tiltrotor development and military and civil demonstrations. The two aircraft have accumulated over $800 \mathrm{hr}$ of accident-free testing.

The advantages of the tilt-rotor aircraft are many. The ease with which the aircraft can be converted from one flight mode to another enhances its maneuverability and permits it to be configured to meet varied mission requirements. Also, the unique tilt-rotor aircraft increases mission flexibility by providing a flight envelope that overlaps those of the helicopter and airplance. Eigure 8 compares an XV-15 tilt-rotor flight envelope with a helicopter and fixed-wing turboprop.

The vibration levels measured in the XV-15 in the helicopter mode are similar to those for helicopters. In the airplane mode, vibration levels are equivalent to other turboprop fixedwing aircraft.

Figure 9 compares measured XV-15 sound exposure levels with those of Bell 222A, which 
is representative of modern helicopters. These measurements were obtained from a flyover at $500 \mathrm{ft}(6)$. Note that the $X V-15$ tilt rotor is significantly quieter than the helicopter, even though it weighs more than twice as much as the helicopter, and has a greater disk loading. Also, the sideline noise drops off much more rapidly on the $X V-15$ than it does on the hel icopter.

The success of the XV- 15 program has led to the development of $V-22$ Osprey tilt-rotor, multimission aircraft by Bell Helicopter Textron and the Boeing Vertol Company for the Department of Defense (DOD). An artist's rendition of the $V-22$ is shown in Fig. 10. The V-22's gross weight is over $45,000 \mathrm{lb}$. The first V-22 is scheduled to fly in the summer of 1988 .

The Federal Aviation Administration (FAA), NASA, and DOD conducted a joint study of civil tilt-rotor aircraft (7). The Boeing Commercial Airplane Company led the main contractual effort, with subcontracts to Bell Helicopter Textron and the Boeing Vertol Company. The study identified the most promising areas of potential application of the civil tilt rotor and led to the five configurations shown in Eig. 11. One configuration is an all-new design that is the same size as the $X V-15$ tilt rotor; two configurations are derivatives of the $\mathrm{V}-22$ military tilt rotor; and two configurations are all new civil tilt rotors. The structural design and propulsion systems used on all of the configurations are of the same technology as the $V-22$ military tilt rotor; these include the twin-engine arrangement, rotors, controls, gearboxes, and driveshaft cross-shafting. The 19-passenger and 39-passenger civil-tilt rotor renditions are shown in Figs. $12 \mathrm{a}$ and $12 \mathrm{~b}$, respectively. The payload-range curve for the 19-passenger configuration is shown in Fig. 13. For vertical takeoff and landing operations with one-engine-inoperative margin, the range is $600 \mathrm{n}$. $\mathrm{mi}$., whereas for STOL operation the range can be more than doubled to nearly $1400 \mathrm{n}$. mi. Six potential market applications were analyzed for the five aircraft sizes as shown in Table 2. The table indicates the broad range of applications of the civil tilt-rotor aircraft. Thus, the tilt rotor could be used to meet many of the transportation needs of the Pacific Basin.

FOLDING TILT ROTOR - The XV-15 research aircraft has demonstrated the tilt-rotor and its operational readiness; however, it was not optimized for high speed. Studies under way at Ames indicate that it will be possible to operate tilt-rotor configurations to 400 knots with advanced technology $(8)$. An improved aeroelastically stable rotor-hub configuration is required along with a lower drag configuration. Beyond 400 knots, rotor drag is severe. However, if the rotor is slowed, stopped, and folded, while the forward thrust is provided by a convertible turbofan engine, this configuration can attain speeds approaching 500 knots. An artist's conception by Bell Helicopter Textron of a folding tilt-rotor is shown in Fig. 14. As with most V/STOL designs, the folding tilt-rotor aircraft idea is not new. In 1970-72, considerable research was performed by both Bell Helicopter Textron and Boeing Vertol on folding tilt-rotor vahicles under NASA sponsorship. The rotor-folding mechanism was tested by NASA and Bell in 1972 in Ames' 40- by 80-ft wind tunnel (Fig. 15). Complete stop-indexfold-unfold cycles were successfully demonstrated with a 25-ft-diam rotor at wind-tunnel speeds as high as 175 knots.

The work done in the early 1970s was based on the utilization of four engines--two for shaft power and two for fan thrust. Today the application of the convertible propulsion technology (i.e., an engine that converts from turbofan to turboshaft) could reduce weight. Considerable effort has been expended in analyzing and testing engines of this type (9). In Eig. 16, the TF-34 modified into a convertible engine is shown in schematic form. A folding tilt rotor with today's technology could be designed to operate at maximum speeds of 475 knots with a altitude ceiling of $40,000 \mathrm{ft}$ (10).

COMPOUND ADVANCING-BLADE CONCEPT - The principle of advancing blade concept ( $A B C$ ) helicopter is based on the use of rigid, coaxial, counterrotating rotors. The $A B C$ is a rotor design that utilizes more of a rotor's lift potential by eliminating retreating blade stall in high speed. Single-rotor helicopters must produce equal lift on each side of the disk to keep the rotor level in roll. To compensate for the unequal distribution in lift, larger pitch angles are required for the retreating blade than for the advancing blade. The $A B C$ rotor avoids this condition by transferring the lift to the advancing blades on each side of the disk, producing a balanced rolling moment. By eliminating retreating-blade stall, an $A B C$ rotor requires less power than a conventional rotor at high speeds and can maintain lift throughout the speed envelope (Fig. 17). Hover performance is superior to single-rotor helicopters because the power train and additional weight of the tail rotor, gearboxes, shafting, and controls are eliminated. 
The $A B C$ was developed by Sikorsky Aircraft beginning in 1964. Preliminary testing included a 1/5-scale, powered wind-tunnel model and a full-scale, 40-ft diam rotor system run in Ames' 40 - by 80 - ft wind tunnel. Based on favorable test results, the U.S. Army awarded Sikorsky a contract to build a technology demonstrator. The $A B C$ demonstrator was designed to be flown both as a pure helicopter and as a compound helicopter (i.e., with auxiliary propulsion system). The flight program initiated in 1973 was sponsored by the Army, NASA, and Navy, and explored the helicopter mode. The flight envelope was then expanded in the compound configuration ( $F i g .18$ ) with the addition of two J-60 turbofet engines to increase its forward speed and agility (11).

The ABC achieved forward speeds of about 240 knots and demonstrated good hover characteristics, high maneuverability, compact size, and relative simplicity, but had high vibration and hub drag at the higher speeds. A flight envelope is shown in Fig. 19. However, because it was purely a concept demonstrator, the blade shape, twist, hub shape, rotor materials, shaft tilt, auxiliary propulsion, empennage, and flight controls were not optimized. The flight program was terminated before improvements could be made in the various aircraft subsystems. A review of the lessons learned from the flight program indicated that the following steps could be taken to improve system efficiency: optimization of rotor-blade airfoil sections for highspeed flight, modified transmissions and structural weight, an integrated propulsion system, and modified empennage and hub for reduced drag. An optimized $A B C$ design has the potential for speeds greater than 250 knots and could have a broad range of applications. A 30-passenger civil ABC has been studied that has a design speed of 250 knots and stage length of $500 \mathrm{miles}$ (Fig. 20).

STOPPED ROTOR - The X-wing is an aircraft with a stoppable rotor that will provide a lowdisk loading VTOL capability, similar to that of a conventional helicopter, combined with high subsonic cruise speed. The rotor is stiff, four-bladed and utilizes circulation-control blowing over the trailing - and leading-edge surfaces of its symmetrical blades for 1 ift and control. The $X$-wing is designed to operate in three different modes: rotary-wing, conversion, and fixed-wing; these are depicted in Fig. 21. In the rotary-wing mode, the $X-w i n g$ rotor is used as conventional helicopter rotor with the addition of blowing to augment lift for hover, the transition to forward flight, and in forward flight at speeds up to approximately 150 knots.
At speeds in the range between 150 and 200 knots, the $X$-wing converts from a rotary-wing to a fixed-wing by reducing rotor speed until the rotor is stopped in a fixed position with two blades swept forward and two blades swept back at $45^{\circ}$. The $X-w i n g$ is designed to operate as a fixed-wing aircraft at flight speeds between 200 and 500 knots. (However, the drag of the vehicle has not been verified at high speeds.) In this mode, the aircraft control is provided in part by the blowing system, which replaces the traditional wing control surfaces.

The $X$-wing evolved from the circulation control work of Ian Cheeseman of the University of Southampton, England, in the 1960s; his work was followed by research at the U.S. Navy's David W. Taylor Naval Ship Research and Development Center. Early wind-tunnel tests were conducted by Lockheed California Company, including conversion of a 25-ft rotor in the Ames $40-$ by $80-\mathrm{ft}$ wind tunnel, followed by $X$-wing assessment by Boeing Vertol and Sikorsky Aircraft.

The RSRA/X-wing program was initiated in 1983 with a contract to Sikorsky Aircraft with funding from Defense Advanced Research Projects Agency and NASA. The $\mathrm{X}$-wing on the Rotor Systems Research Aircraft (RSRA) is shown in Fig. 22. The RSRA is a compound configuration developed as a "flying wind tunnel" for evaluating new rotor designs under actual flight conditions. The current RSRA aircraft is limited to 250 knots.

A number of critical technologies are being developed for the RSRA/X-wing program. These include: (1) very stiff composite structures for obtaining the high natural frequencies of the rotor-wing to avoid aeroelastic problems and to provide satisfactory control; (2) digital fly-by-wire control systems for good handling in the various flight modes, controlling vibration, and implementing the control laws for stopping and starting the rotor wing; and (3) a pneumodynamic control system that consists of 48 valves that control the air supply to the leading and trailing edges of the blades. In addition, convertible engines are being developed for propulsion system simplication and weight reduction (Eig. 16).

The broad goal of the RSRA/X-wing program is to develop specific technology and demonstrate conversion between rotary-wing and fixedwing modes. These activities are anticipated to provide the necessary technology base so that a low-risk development program could be initiated for a prototype vehicle. The rollout of the RSRA/X-wing vehicle occurred in August 1986 and flight testing is planned for 1987 and 1988. 
Even though the $X$-wing is extremely complex and involves a number of technical hurdles that must be overcome before the design becomes feasible, it has potential for both military and civil applications. A discussion of X-wing potential for Navy applications is given in Ref. 12. A civil version of this concept is shown in Fig. 23. An X-wing aircraft with advanced-technology convertible engines could be designed to operate at speeds of 500 knots and at altitude ceilings greater than $40,000 \mathrm{ft}$.

\section{SUBSONIC V/STOL CONFIGURATIONS}

There is a long history of V/STOL and vertical takeoff and landing (VTOL) aircraft developments in the United States $(13,14)$. This section will consider three types of subsonic configurations to illustrate a range of potential vehicles and applications: liftcruise fan, tilt wing, and vectored thrust. LIFT-CRUISE FAN - Lift-cruise fan VTOL aircraft are generally characterized by utilizing high-bypass-ratio fans for thrust in cruise, and for lift in terminal-area flight. In transition and cruise flight, the lift-cruise fan thrust vector is rotated down by rotation of the entire nacelle, or by rotation of the nozzle exits and louvers. (The U.S. Navy and NASA cooperatively developed the technology basis for the design of lift-cruise fan V/STOL aircraft for both military and commercial applications.) The design depicted in Fig. 24 employed three fans driven by two engines. A full-scale wind tunnel model of this configuration was designed and built by McDonnell Douglas and tested in the Ames 40 - by $80-\mathrm{ft}$ wind tunnel (15). The two engines drove turbofans mounted over the wing. The thrust of these two fans could be vectored through a D-nozzle to provide either vertical lift or cruise thrust. A third fan, located in the nose of the aircraft, was driven through a gearbox arrangement connected to the two engines.

An example of a design in which the entire nacelle rotates is the tilt-nacelle configuration designed and built by Grumman Aircraft. The design incorporates two tilting, high-bypass turbofan engines with controllable inlet guide vanes and a system of controllable vanes in the engine exhaust flow (Fig. 25). Hover control is achieved through direct modulation and angling of the fan thrust vector, thereby eliminating the need for a reaction control system. Aerodynamic vanes located behind the nacelles in the fan-core engine exhaust provide pitch and yaw control; thrust modulation provides height and roll control.
The tilt-nacelle has evolved from extensive configuration studies, supported by over $5,000 \mathrm{hr}$ of wind-tunnel tests and flight simulation (16). Nacelle component development testing began in 1976 and has continued to the present time. Initial testing concentrated on developing two of the key components of the propulsion system--the inlet and the control vane assembly. These tests and supporting analyses were used to develop a baseline tiltnacelle configuration (known as the Grumman 698). The tilt-nacelle configuration was tested extensively, using small-scale windtunnel models and using a large-scale model in both the hover facility and the 40- by $80-$ ft wind tunnel at Ames (Fig. 26). The wind-tunnel results indicate that the configuration can operate over a broad transition corridor with ample maneuver capability. The ground research program indicated no technical show stoppers. The tilt-nacelle has been proved during extensive tests, and the technology is ready to proceed with a low-risk program for a manned flight demonstrator. The tilt-nacelle offers moderate hover endurance capability, a less complex control system because of no-enginebleed requirement and a good propulsion-airframe match throughout the flight envelope. It is particularly suited for long endurance, moderate hover, and high-altitude missions. Many missions, particularly civil missions, require no hover endurance, but do require vertical flight capability. The wind-tunnel model represented a proposed manned flight demonstrator aircraft, which would weigh about $16,000 \mathrm{lb}$ and be powered by TF-34 engines.

A study of civil transportation missions for the tilt-nacelle was reported in Ref. 17. A tilt-jet VTOL aircraft was modeled after the tilt nacelle design, using near-term advanced technology levels. The results from this study of payload versus range for an executive transport mission are shown in Fig. 27. For the mission, the payload was 1,400 lb for a $95^{\circ} \mathrm{F}$-day takeoff and a 750-mile range. The study showed that the tilt-nacelle transport is most costeffective at long ranges because of its high cruise speed.

TILT WING - Propeller V/STOL aircraft have a long history dating back to the early 1950s when research was intiated on both the deflected slipstream STOL and the tilt-wing V/STOL. In the deflected-slipstream design, near vertical thrust is obtained by turning the propeller slipstream downward with large wing flaps, while maintaining the wing and propellers in an essentially horizontal attitude. In the tilt-wing, the wing and propellers are tilted up at a 
$90^{\circ}$-attitude for takeoff and landing. The second-generation demonstrator tilt-wing airplanes built in the 1960 s were the LTV-HillerRyan XC-142A and the Canadiar CL-84. The $X C-142 A$ was the winning entry in the Tri-Service $V / S T O L$ transport competition of 1961. The $X C-142 \mathrm{~A}$ ( $\mathrm{Fig}, 28$ ) used four T64-GE-1 engines with cross-shafting to four propellers and a tail propeller for pitch control. A schematic of the tilt-wing aircraft is shown in Fig. 29.

Because the aircraft was built as a concept demonstrator and not as a prototype, the XC-142A flight program disclosed several mechanical and structural problems requiring further development. However, the CL-84 program which flew several years later had fewer problems. The XC-142A and CL-84 programs were generally considered successful in that they demonstrated very effectively the VTOL and STOL capabilities of the tilt-wing concept for operational use. The performance envelope for the XC-142A is shown in Fig. 30. Other development work since the XC-142A program indicated a $50 \%$ reduction in propeller and transmission system weight could be achieved with advanced technology. Also, advanced technology could improve the handling qualities, in-ground effect, and propeller noise levels.

VECTORED THRUST - The only operational $V / S T O L$ fighter aircraft in the free-world today is the Harrier. The U.S. Marine Corps has been using the British AV-8A Harrier vectored-thrust aircraft since 1971. The Marines now use the $A V-8 B$ version of the Harrier built by McDonnell Douglas Aircraft Company; it incorporates a number of modifications that improved range and payload. The prototype of the AV-8B is currently being used as a V/STOL research aircraft at Ames for investigations into integrated flight propulsion controls, aerodynamics, and advanced displays (Fig. 31). The Harrier, being a high-disk loading aircraft, is ideal for high speed and high maneuverability military applications.

\section{STOL TRANSPORATION OPPORTUNITIES}

Short takeoff and landing (STOL) aircraft have the potential for relieving congestion at hub airports, transporting tourist and highvalue cargo, and aiding in the development of regions. STOL aircraft can avoid the problems of landing-slot allocation and long arrival and departure delays by utilizing the short segments of inactive runways, stub-runways, or special STOL runways which are typically 2,000 ft long (see Fig. 5). STOL ports can be categorized as two basic types: CTOL/STOL ports consisting of one or more STOL runways situated at a CTOL airport; and independent STOL ports consisting of one or more STOL runways situated at a site removed from a CTOL airport.

STOL aircraft offer a distinct advantage over the CTOL aircraft by using shorter runways and because of their inherent characteristics to descend and climb steeply. STOL operations to and from a STOL port offer a great deal of flexibility in providing discrete routes to facilitate traffic flow. Airspace required by STOL aircraft for takeoff/landing and in terminal-area maneuvering is significantly less than that required by CTOL aircrart. These characteristics not only facilitate operation of the ATC system in segregating STOL and CTOL traffic, but also assist in carrying out obstruction-clearance and noise-abatement procedures. The curving, steep-gradient flight paths of STOL aircraft can be arranged to avoid adverse effects caused by wake vortices from heavy CTOL aircraft.

Suitable sites for STOL airports can be found even in congested cities. Similar to $\mathrm{V} / \mathrm{STOL}$ aircraft, STOL airports could be located along rivers, along the shores of large bodies of water, along transportation rights-of-way, or in wasteland areas within cities that are unsuitable for housing or industry. For example, a STOL landing pad could be located along the riverfront $(e . g .$, as is the new STOL port in London), or could be built on the roofs of existing waterfront buildings, or on unused piers. In remote areas STOL aircraft could be used on short, unpaved runways that are relatively easy to construct.

\section{SUBSONIC STOL CONFIGURATIONS}

A STOL aircraft is generally defined as one that can take off or land over a 50-ft obstacle at sea level at its maximum takeoff or landing weight in a distance of about 2,000 ft (or less). Historically, operational STOL aircraft have achieved their short-field performance through light-wing loading ( $25 \mathrm{lb} / \mathrm{ft}^{2}$ or less) and extensive use of high lift devices such as flaps and slats, at the expense of reasonably high cruise efficiency and poor-ride qualities. Various designs have been powered by turboprop-turboshaft and pure jet propulsion systems. Current STOL aircraft that are being used for commuter aircraft operations include the De Havilland Twin Otters and Dash $7 \mathrm{~s}$. Typically, these aircraft accommodate fewer than 60 passengers and cruise at speeds less than 250 knots. 
Future and larger STOL aircraft must have the necessary short-field and maneuvering envelope to get into and out of hub airports separately from CTOL aircraft and have minimum environmental effects at the small secondary urban airports. Promising technology for future designs was developed under the U.S. Air Force Advanced Medium STOL Transport Program which produced the YC-14 and YC-15 military prototype aircraft, the NASA Augmentor-Wing Research Aircraft Program, and the NASA Quiet Short-Haul Research Aircraft (QSRA) Program. This technology can be applied to a new generation of large high-speed transport airplanes with outstanding short-field capability. Figure 32 illustrates these aircraft and simplified schematics of the lift-augmentation systems. The externally blown-flap system concept from the YC-15 prototype will be used on the C-17, which is currently under development for the Air Force. The lift augmentation is achieved by flaps deflecting the thrust downward on takeoff and landing, with the flaps retracted during high-speed cruise flight. The Augmentor-Wing Jet STOL Research Aircraft ejects fan bleed air between wing upper and lower flap segments for lift augmentation.

The upper surface blowing (USB) design utilizes high wing loading which results in improved ride qualities over those of the curcent low-wing-loading aircraft. An example of the USB design is the twin engine YC-14 aircraft. The high performance of USB aircraft is achieved by installing the engines over the forward portion of the wing. A faired mixing nozzle directs the exhaust gases over the wing's upper surface and flaps to provide increased aerodynamic lift. Lift is improved by taking advantage of the Coanda effect (Fig. 33), where air adhering to the surface of the wing continues down over a highly deflected flap, converting a large portion of the jet thrust into propulsive lift.

The four-engine QSRA (18) was developed for proof-of-concept verification of the USB lowspeed-flying characteristics and has been used extensively to investigate terminal-area operations for STOL aircraft (see Fig. 34). This four-engine USB configuration offers better engine-out performance than a two-engine configuration. Flight research with the QSRA has also confirmed that landing performance at relative short field lengths can be achieved at the lower thrust-to-weight ratios comparable to those used in conventional aircraft. The QSRA nominal takeof $f$ and landing distance is $750 \mathrm{ft}$ and $650 \mathrm{ft}$, respectively. However, during carrier trials, the QSRA demonstrated takeoff distances less than $300 \mathrm{ft}$ and landing distances less than $200 \mathrm{ft}$.

For optimum utilization, a STOL aircraft requires a high approach angle capability to minimize the required air space into the terminal area. The USB nozzle and flaps on the QSRA have been designed for exceptionally high turning of the engine exhaust airflow to enable steep approach angles with adequate safety margins. The approach path is over twice as steep as that of conventional airplanes; Fig. 35 illustrates this point. Note that the QSRA can touch down and stop before the CTOL touches down. Since noise attenuates rapidly with distance (height), the higher approach attitude is a big factor in reducing the noise effect on the surrounding community. This height is increased even more by landing such aircraft away from the boundaries of the airport.

The QSRA uses the Lycoming YF-102 engine which has a relatively high bypass ratio ( 6 to 1), which, in turn, is conducive to low noise. The installation has been designed specifically to attenuate the engine noise by including tuned acoustic linings in the inlet and fan duct. In addition, placing the engine above the wing provides noise shielding to ground observers. These design features result in an extremely quiet airplane, as exemplified by comparing the 90-EPNdB footprint of a "scaled-up" QSRA airplane to that of a commercial jet transport (Fig. 36). The noise footprint is significant in that it indicates the effect of the airplane's noise on the area around the airport. Studies have shown that the noise reaching the surrounding community will be well below the 90-EPNdB level. For example, even for this "scaled-up" QSRA, the 90-EPNdB noise level has been calculated to be essentially contained within typical airport boundaries.

Since transport aircraft spend a large portion of their flying time at cruise speeds, an investigation is required to minimize cruisedrag associated with USB. It is anticipated that computational analysis, wind-tunnel testing, and flight measurements will be required before a commitment is made to a production program. Further, verification will be obtained from the Quiet Short Takeoff and Landing (QSTOL) airplane called the Asuka. The Asuka, using USB technology, is designed to operate at Mach 0.7 , with a ceiling of $30,000 \mathrm{ft}$ and a maximum range of 1,000 miles. It began flight testing in October 1985 (Fig. 37). The Asuka was developed by the Japanese National Aerospace Laboratory and a consortium of Japanese companies. 
In summary, large transport aircraft that utilize powered lift can offer impressive shortfield performance, increase payload for CTOL operations, and reduced noise level. They can increase the capacity of existing airports by providing service on STOL runways using alternative-airport approach paths. These aircraft may also provide airline service to secondary airports that currently have no airline service.

\section{COMPARISON OF CONFIGURATIONS}

Disk loading can be used as an important parameter to identify the relative merits of configurations. Disk loading is defined as the maximum thrust produced divided by an appropriate cross-sectional area of the thrust producing device. Generally, aircraft hover performance can be related to it. As disk loading increases, hover efficiency (thrust per unit power) decreases markedly, as shown in Fig. 38. A lift system that imports a high downwash velocity is less efficient because the engine power (and fuel flow required to produce the lift) varies as the cube of the air velocity. This directly affects hover performance (Fig. 39). The fuel required to hover (expressed in pounds of fuel per minute) is plotted versus the cruise speed of the aircraft. Considering that operational aircraft normally only have 0.25 to 0.30 fuel fraction available, the hover requirements of the intended mission are an important consideration in design selection. It is obvious from Fig. 39 that even at low hover times the fuel used by vectored thrust and lift-cruise fan designs is significant. For these designs it is important to develop operational techniques and pilot aids to minimize the time spent in hover and at very low speeds. Also, notice in Fig. 39 that the $X$-wing, which is representative of stopped-rotor designs, is a means of achieving high speeds while maintaining good hover efficiency. However, this assumes that the $\mathrm{X}$-wing has a satisfactory lift-to-drag (L/D) ratio at cruise speeds, a characteristic that remains to be determined.

The effect of configuration on flight performance can be examined by considering the flight envelope of the low-disk loading aircraft (Fig. 40). It can be observed that as speed and altitude increase, the complexity of the vehicle increases, as well as the power required, which results in higher empty-weight fractions (empty weight/gross weight). However, the increased higher speed or range could make the vehicle economically feasible. The helicopter is limited to less than about 200 knots and has empty-weight fractions of 0.5 to 0.6 . A compound helicopter requires additional engine weight and heavier rotor system that increase empty weight. The tilt rotor has an aerodynamic lifting surface in addition to the tilting mechanism, resulting in an empty-weight fraction of 0.67-0.70. The speed and altitude are further increased by stopping and folding the rotors and substituting convertible engines. The additional complexity also increases the weight and power required. Finally, the stopped-rotor $X$-wing has the highest speed and altitude potential; however, complexity and weight increases because of the large rigid rotor system, the associated pneumodynamic system, and installation of the convertible engine. The result is empty-weight fractions from 0.69 to 0.75 .

The flight envelopes of high-disk-loading aircraft are illustrated in Fig. 41. These envelope limits are similar to those of CTOL aircraft using the same propulsion system. However, V/STOL aircraft tend to have small wing areas and spans because at low speeds they are not dependent on aerodynamic lift. The principle aerodynamic parameter affecting aircraft range is the maximum lift-to-drag ratio, which is a function of wing span squared divided by the total wetted area. Hence, V/STOL aircraft may have lower cruise $L / D$ than CTOLs. In addition, some designs will have greater wetted areas because their total volume will be greater owing to the inclusion of additional components for propulsion or, for example, gas ducting and nozzle-deflecting mechanisms. Also, the aircraft designer has less freedom in positioning components because of packaging and center-ofgravity location constraints and limited inlet location placement to avoid recirculationreingestion problems.

In civil applications, environmental factors are extremely important operational considerations, especially for landing sites. Figure 42 compares the predicted perceived noise level ( $\mathrm{PNdB}$ ) of various thrusting devices that are characterized by disk loading. The power plants are at full-power setting and the distance of the noise detector from the aircraft is $400 \mathrm{ft}$. As a baseline, the noise level of typical city daytime traffic is 80 to $90 \mathrm{PNdB}$. Hence, the noise level is extremely important in site selection, as well as in determining the design for the mission. Generally, the noise level increases as the disk loading increases. High-disk-loading vehicles may have noise levels unacceptable in dense urban environments but acceptable in remote regions. 
Another operational problem that must be considered is the downwash pattern from the thrusting device. Figure 43 shows the velocity at ground level due to downwash from aircraft of various disk loadings (19). Note that the higher the disk loading, the smaller the boundary-layer thickness and the higher the maximum boundary-layer velocity. Hence, the high-disk-loading vehicles require a prepared clean surface, whereas the lower-disk-loading aircraft can land on less prepared surfaces and not adversely affect the surrounding area. Another operational factor is the hot exhaust gas impingement problem prevalent with vectoredthrust configurations. The impingement of the hot gases on the landing surface can damage the surface and in some cases may break up the surface and coat or impinge the surrounding area with eroded surface material. Thus, a treated landing pad area may be required to withstand high-temperature exhaust.

To determine the $r$ ight $V / S T O L$ aircraft for a particular application requires a mission analysis subject to mission constraints, such as operating environment and type of landing site. Two examples of this type of analysis are shown in Figs. 44 and 45 . The first example (Fig. 44) shows the mission gross weights for a helicopter, ABC, tilt rotor, and lift-cruise fan for a rescue mission. The same payload was used for the four configurations. The mission requires flying over 300 miles, hovering out-of-ground effect for $8 \mathrm{~min}$ at $7,000 \mathrm{ft}$ on an $83^{\circ} \mathrm{F}$ day, then returning to the base, which is at 4,000 ft on a $95^{\circ} \mathrm{F}$ day. It is seen that the tilt rotor is the lowest gross weight vehicle to perform the mission. Its gross weight is 43,000 $1 \mathrm{~b}$ and its average cruise speed is 280 knots. On the other hand, the helicopter's mission gross weight is over $51,000 \mathrm{lb}$ and its average cruise speed is 198 knots. The lift-cruise fan average cruise speed is 450 knots; however, the 8-min hover out-of-ground effect requirement requires the vehicle to carry a lot more fuel because of its hover inefficiency; as a result, its gross weight is $62,000 \mathrm{lb}$. The $A B C$ was the heaviest vehicle at 74,000 $1 \mathrm{~b}$. This was primarily attributed to the cruise inefficiency resulting from overcoming the drag of the coaxial hub.

A longer range example is shown in Fig. 45 . This transport mission requires a range of 800 miles, taking off vertically at sea level on a $90^{\circ} \mathrm{F}$ day, and landing vertically at 5,000 ft above sea level on a $90^{\circ} \mathrm{F}$ day. In this case the lift-cruise fan is the lowest mission gross weight vehicle. This is due to both the increased distance compared with the first example and a requirement only to take off and land vertically. Hence, the lift-cruise fan's efficient cruise gives it a large advantage over the other designs. The tilt rotor is 1.5 times heavier, whereas the helicopter is almost 2 times heavier. For the ground rules of the study comparison, the $A B C$ could not fulfill the mission at any practical gross weight. In addition, the lift-cruise fan cruise speed is 450 knots, whereas the helicopter cruise was 100 knots, and that of the tilt rotor at 260 knots. Thus, the lift fan arrived in less than half the time required by the other two vehicles. For different mission requirements other V/STOL configurations may have the lower gross weights. It is also known that venicle cost is directly correlated to the venicle weight.

It should be added that important civil certification requirements, such as fuel reserve and one-engine inoperative margin, are in the process of being addressed, but not finalized in the United States. The ability to operate safely after loss of an engine and being able to fly precisely and stably at low landing speeds for instrument flight-rule operation are essential.

\section{APPLICATIONS OF CONEIGURATIONS TO PACIEIC BASIN}

As discussed in the sections on V/STOL and STOL transportation opportunities, many of the configurations discussed can be of great benefit to the Pacific Basin region because of the varied distance requirements (short to long haul) and geographic constraints. The greatest opportunities appear to be for smaller vehicles (fewer than 50 passengers) which make the future especially attactive for $\mathrm{V} / \mathrm{STOL}$ aircraft. The civil applications of the configurations discussed as they apply to the Pacific Basin are summarized in Table 3, along with estimated operating ranges that vary from $300 \mathrm{n}$. mi. for compound $\mathrm{ABC}$ to $3,000 \mathrm{n}$. mi. for a STOL aircraft. In addition to range, other factors that determine the configuration applicability are productivity (speed and payload), fuel efficiency, hover, economics, noise, and downwash characteristics. Generally, the lowest-grossweight vehicle will have the most favorable economics and fuel efficiency.

The potential applications are (1) commuter airlines, which include airport congestion relief as a benefit where economics and noise are prime factors; (2) tourism, where economics, noise, and landing surface preparation are important; (3) high-value cargo, where speed and range are factors; (4) resource development, including fishing, high-grade mining and oil; 
(5) developing-region utility vehicle; and (6) public service, which includes public safety-law enforcement, where noise is important, air ambulance, fire fighting, and disaster relief.

By applying the important factors along with the $V / S T O L$ configuration performance and operating characteristics, potential applications for the various designs were determined (Table 3). The compound $A B C$, tilt rotor, tiltwing, and $X-w i n g$ aircraft are best suited to commuter airline service. The lift-cruise fan was excluded because of high downwash. Tourism for remote areas appears especially attractive for the compound $A B C$, tilt rotor, and $X-w i n g$, because of the requirement of landing on lesser prepared surfaces. All designs may be suitable for high-value-cargo and resource development, and as developing-region utility vehicles. The particular vehicle selected would depend on the speed, range, and hover requirements. Public service missions (public safety and law enforcement, air ambulance, fire fighting, and disaster relief) are currently being performed primarily by helicopters. Public service/law enforcement and air ambulance missjons greatly favor the low-disk loading, shorter-range vehicles--ABC, tilt rotor, and $X-w i n g$ because of hover requirements. In addition to the low-disk loading vehicles, the tilt wing, and lift-cruise fan can be used for fire fighting in place of the fixedwing aircraft used today--primarily for dispersing fire retardant to contain fires. Also, all configurations could be utilized for relief in cases of man-made and natural disasters.

If a STOL runway is available and hover is not a requirement, the STOL vehicle has the many potential applications shown in Table 3, especially if a larger size vehicle is desired. All of the described applications are transportation opportunities that should be of great benefit to the Pacific Basin region.

\section{CONCLUDING REMARKS}

Future opportunities for V/STOL and STOL applications appear to be enormous for the Asian-Pacific region. Large economic benefits can accrue through the use of these types of aircraft to provide rapid and flexible transportation, which overcomes the lack of suitable airport facilities and formidable geographic barriers. At the same time, these aircraft can relieve congestion at regional airports, advancing the potential for unconstrained aviation growth. In short, these aircraft hold the promise to revolutionize short haul transportation.
The tilt-rotor design is closest to readiness for civil applications because of the timely development of the V-22 for military use. However, if planners develop an integrated transportation system utilizing the capabilities of the V/STOL and STOL aircraft described, several of the aircraft designs could be operational within a decade (providing a strong commitment was made by the public and private sectors).

Finally, a future scenario is described. An airport of the future is shown in Fig. 46. The year is 2015. The "Orient Express" hyper sonic cruise aircraft is transporting passengers and high-value cargo from the United States and Europe in less than $3 \mathrm{hr}$ to a remote airport located offshore of Japan or in the desert in northeastern Australia. From here, in addition to the Orient Express aircraft and conventional CTOL aircraft, V/STOL and STOL aircraft are operating. These latter aircraft are enabling the airport to be uncongested, to readily accept future growth, and to provide rapid point-topoint transportation everywhere in the region from the most densely populated regions through the most inaccessible regions in the Basin.

Each of the aircraft configurations described has its merits. Examples of the application of these configurations are as follows. The compound $A B C$ helicopter carries critical parts to a gold mine in central Australia. The tilt rotor provides transportation to the downtown Sydney waterfront. The $X$-wing rapidly transports urgently needed medical supplies to Micronesia. The tilt wing transports tourists to the Great Barrier Reef islands. The tilt nacelle delivers an urgently needed part for an offshort oil rig in Indonesian territorial waters. Finally, the STOL aircraft transports businessmen to Perth. We recommend that a detailed study be initiated to evaluate these promising configurations in order to determine one or two configurations that should be considered for development for civil applications. The study should include total transportation system cost tradeoffs. Some day, it is hoped, civil V/STOL and STOL configurations will be operational realities. 


\section{REFERENCES}

1. Anon: "Region's Rapid Economic Growth Enhances Appeal," USA Today, May 20, 1985.

2. Williams, R. M., "National Aerospace Plane: Technology for America's Future," Aerospace America, Nov. 1986.

3. Gobetz, F. W., Assarabowski, F. W., and LeShane, A. A., "Applications of Advanced Transport Aircraft in Developing Countries," NASA CR-145343, 1978.

4. Millhouse, J., "Australia's Helicopter Market," Vertiflight, Vol. 32, No. 3, May-Jun. 1986.

5. Ward, John F., "Rotorcraft Research - A National Effort," The 1986 Alexander Nikolsky Honorary Lecturship, Journal of the American Helicopter Soclety, Vol. 32, No. 2, Apr. 1987.

6. Brieger, J. T., Maisel, M. D., and Gerdes, R., "External Evaluation of the XV-15 Illt Rotor Aircraft," Paper No. B-87-SW-32-D000, Annual National Forum of the American Helicopter Society, Arlington, Texas, Feb. 1987.

7. "Civil Tilt Rotor Missions and Applications: A Research Study," NASA CR-177452, Jul. 1987.

8. Johnson, W., Lon, B. H., and Bowles, J. v. , "Calculated Performance, Stability, and Maneuverability of High Speed Tilting Proprotor Aircraft," Vertica, Vol. 11, No. 112, 1987, pp. 317-339.

9. McArdle, J. C. and Wenzel, L. M. "Experimental Program for the Evaluation of Turbofan/Turboshaft Conversions Technology," NASA TM-82988, 1982.

10. Eisenberg, J. D. and Bowles, J. V., "Folding Tilt-Rotor Demonstration Feasibility Study," Paper No. 06-01, Vol. 2, Annual National Forum of the American Helicopter Society, Washington, D.C., 1986.
11. Rudde11, A. J., et al., "XH-59A ABC Technology Demonstrator Envelope Expansion and Operational Tests," U. S. Army Aviation Research and Development Command TR-81-D-35, Fort Eustis, VA, Dec. 1981.

12. Linden, A. W. and Biggers, J. C., "X-Wing Potential for Navy Applications," 4 ist Annual Forum of the American Helicopter Society, Fort Worth, Texas, May 15-17, 1985, pp. 435-450.

13. Nelms, W. P. and Anderson, S. B., "V/STOL Concepts in the United States, Past, Present, and Future," Paper in AGARD-R-710, Special Course on V/STOL Aerodynamics, Apr. 1984.

14. Lindenbaum, B., "V/STOL Concepts and Development Aircraft. Vol. I - A Historical Report (1940-86)," Air Force Wright Aeronautical Laboratories TR-86-3071, Vol. I, Nov. 1986.

15. Gambucc1, B. J., Aoyagi, K., and Rolls, L. S., "Hind Tunnel Investigation of a LargeScale Model of a Lift-Crulse Fan V/STOL Aircraft with Extended Lift-Cruise Nacelles," NASA TMX-73164, 1976.

16. Lehman, C. and Crafa, V., "Nacelle Design for Grumman Design 698, V/STOL," SAE Paper 831492, Oct. 1983.

17. Wilson, S. B., Bowles, J. V., and Eoster, J. D., "Analysis of Selected VTOL Concepts for a Civil Transport Mission," AIAA Paper 81-2655, 1981.

18. Cochran, J. A., Riddle, D. W., and Youth, S., "Application of Advanced Upper Surface Blowing Propulsive-Lift Technology," SAE Paper 820956, Aug. 1982.

19. Kohlman, D. L., "Introduction to V/STOL Alrplanes," Iowa State University Press, Ames, Iowa, 1981. 
Table 1. Capacity on Major Domestic Japanese Routes (September 1986)

\begin{tabular}{lcc}
\hline \multicolumn{1}{c}{ Route } & $\begin{array}{c}\text { Average } \\
\text { n.me, }\end{array}$ & $\begin{array}{c}\text { One-Way } \\
\text { Seats, Weekly }\end{array}$ \\
\hline Tokyo-Sapporo & 440 & 83,914 \\
Tokyo-Osaka & 220 & 63,875 \\
Tokyo-Fukuoka & 475 & 55,271 \\
Sapporo-Osaka & 562 & 20,160 \\
Tokyo-Kagoshima & 505 & 19,022 \\
Osaka-Fukuoka & 258 & $17,66 i$ \\
Kagoshima-Osaka & 297 & 14,595 \\
\hline
\end{tabular}

Table 2. Applications for Civil Tilt Rotor

\begin{tabular}{|c|c|c|c|c|c|}
\hline \multirow[t]{2}{*}{ Applications } & \multicolumn{5}{|c|}{ Seats } \\
\hline & 8 & 19 & 31 & 39 & 75 \\
\hline High-Density Passenger & & & & $x$ & $x$ \\
\hline Cargo/Package Express & & & $x$ & $\mathrm{x}$ & $x$ \\
\hline Developing Region & & & $\mathrm{x}$ & $x$ & \\
\hline Resource Development & & $x$ & $x$ & $x$ & \\
\hline Public Service & $x$ & $x$ & $x$ & $x$ & \\
\hline Corporate/Executive & $x$ & $x$ & & & \\
\hline
\end{tabular}

Table 3. Applications of Configurations to Pacific Basin

Configurations and Range

\begin{tabular}{|c|c|c|c|c|c|c|}
\hline Application & $\begin{array}{l}\text { Compound ABC } \\
300 \mathrm{n} . \mathrm{mi} \text {. }\end{array}$ & $\begin{array}{l}\text { Tilt Rotor } \\
600 \mathrm{n} . \mathrm{mi}\end{array}$ & $\begin{array}{l}X-W i n g \\
1000 \text { n. mi. }\end{array}$ & $\begin{array}{l}\text { Tilt Wing } \\
600 \mathrm{n} . \mathrm{mi} \text {. }\end{array}$ & $\begin{array}{l}\text { Lift/Cruise } \\
\quad \text { Fan } \\
1800 \mathrm{n} . \mathrm{mi}\end{array}$ & $\begin{array}{l}\text { STOL } \\
3000 \mathrm{n} . \mathrm{mi}\end{array}$ \\
\hline $\begin{array}{l}\text { Commuter (Airport } \\
\text { Congestion Relief) }\end{array}$ & $x$ & $x$ & $x$ & $x$ & & $x$ \\
\hline $\begin{array}{l}\text { Tour ism (Remote } \\
\text { Areas) }\end{array}$ & $x$ & $x$ & $x$ & & & \\
\hline High Value Cargo & $\mathrm{x}$ & $x$ & $x$ & $x$ & $x$ & $\mathrm{x}$ \\
\hline $\begin{array}{l}\text { Resource Development } \\
\text { Fishing } \\
\text { High Grade Mining } \\
\text { Oil }\end{array}$ & $\begin{array}{l}x \\
x \\
x\end{array}$ & $\begin{array}{l}x \\
x \\
x\end{array}$ & $\begin{array}{l}x \\
x \\
x\end{array}$ & $\begin{array}{l}x \\
x \\
x\end{array}$ & $\begin{array}{l}x \\
x \\
x\end{array}$ & $\begin{array}{l}x \\
x \\
x\end{array}$ \\
\hline $\begin{array}{l}\text { Developing Region } \\
\text { Utility Vehicle }\end{array}$ & $x$ & $x$ & $x$ & $x$ & $x$ & $x$ \\
\hline $\begin{array}{l}\text { Public Service } \\
\text { Public Safety/ } \\
\text { Law Enforcement } \\
\text { Air Ambulance } \\
\text { Fire Fighting } \\
\text { Disaster Relief }\end{array}$ & $\begin{array}{l}\mathrm{x} \\
\mathrm{x} \\
\mathrm{x} \\
\mathrm{x}\end{array}$ & $\begin{array}{l}x \\
x \\
x \\
x\end{array}$ & $\begin{array}{l}\mathbf{x} \\
\mathbf{x} \\
\mathbf{x} \\
\mathbf{x}\end{array}$ & $\begin{array}{l}x \\
x\end{array}$ & $\begin{array}{l}x \\
x\end{array}$ & $\begin{array}{l}x \\
x\end{array}$ \\
\hline
\end{tabular}




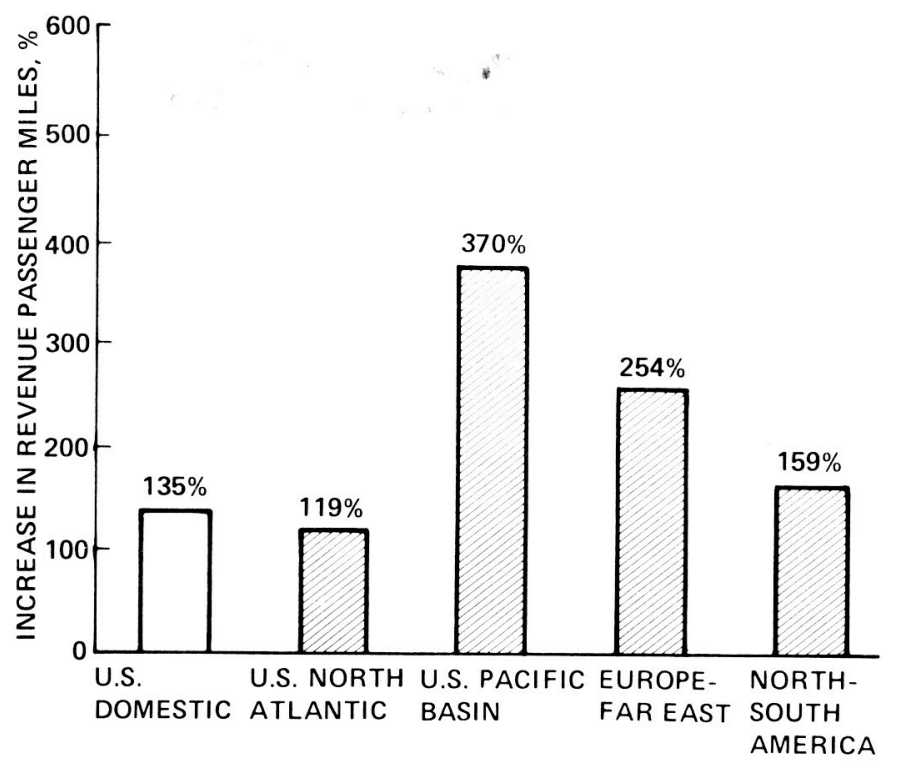

Fig. 1 Projected airline passenger traffic growth, 1985-2000.

\section{ORIGINAT PAOT IS DE ROOR QUALITY}

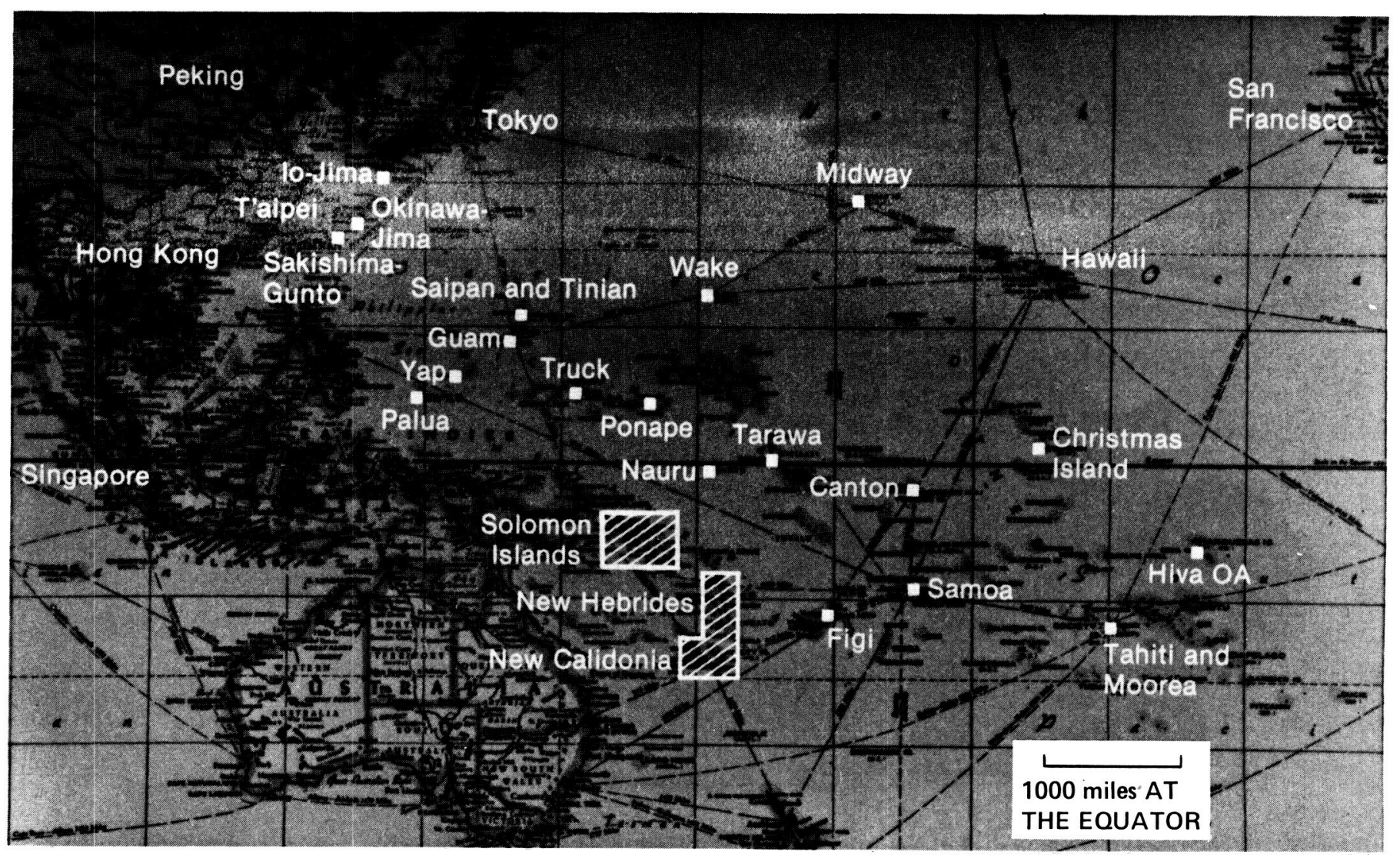

Eig. 2 Pacific Basin. 


\section{DiGINAE RAGE IS \\ ON POOR OINIITY}

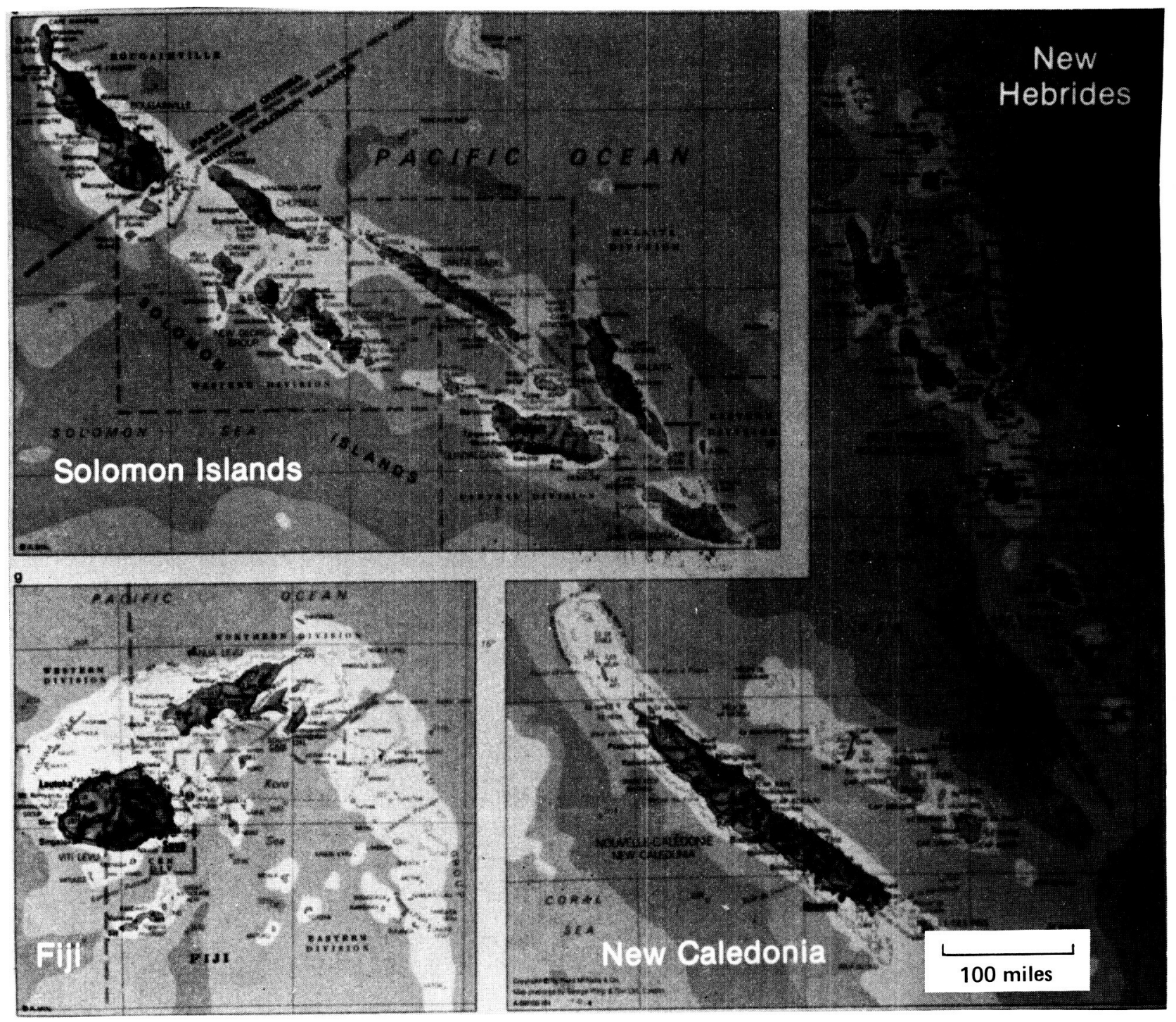

Fig. 3 Representative island groups within Pacific Basin. 


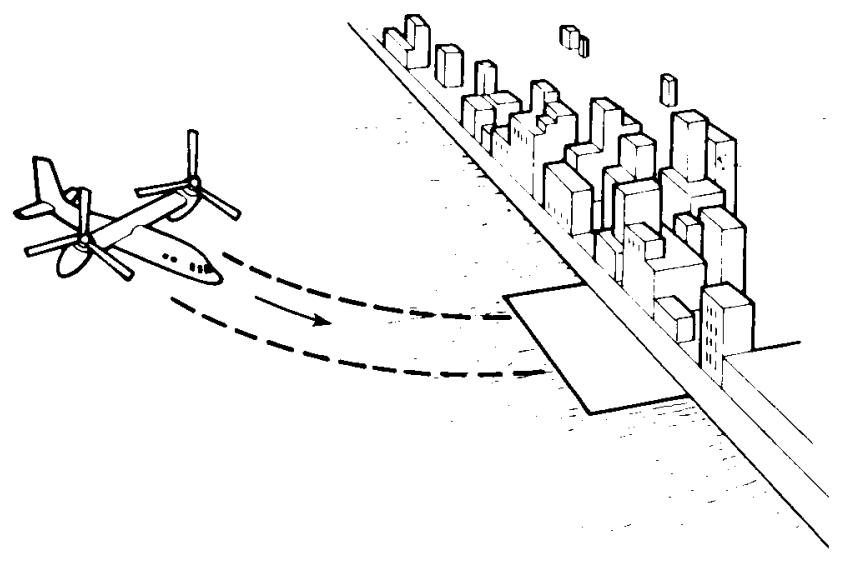

(a) SEAPORT

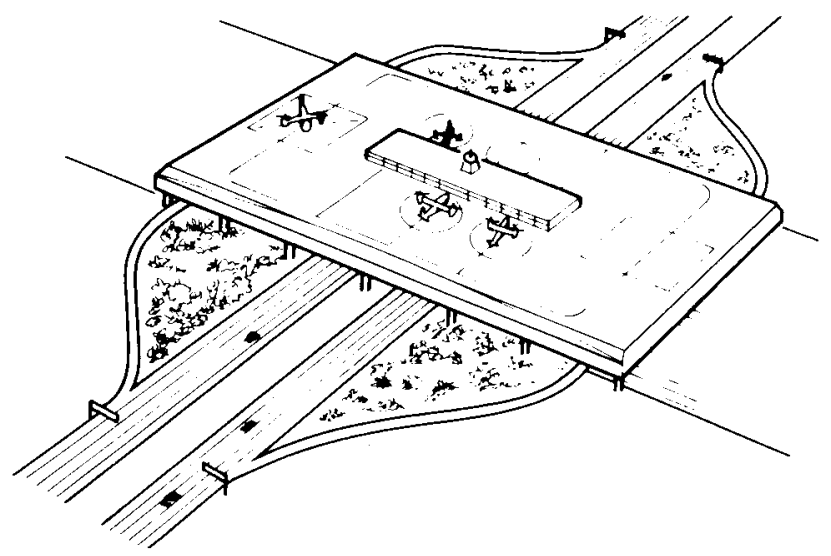

(c) FREEWAY PORT

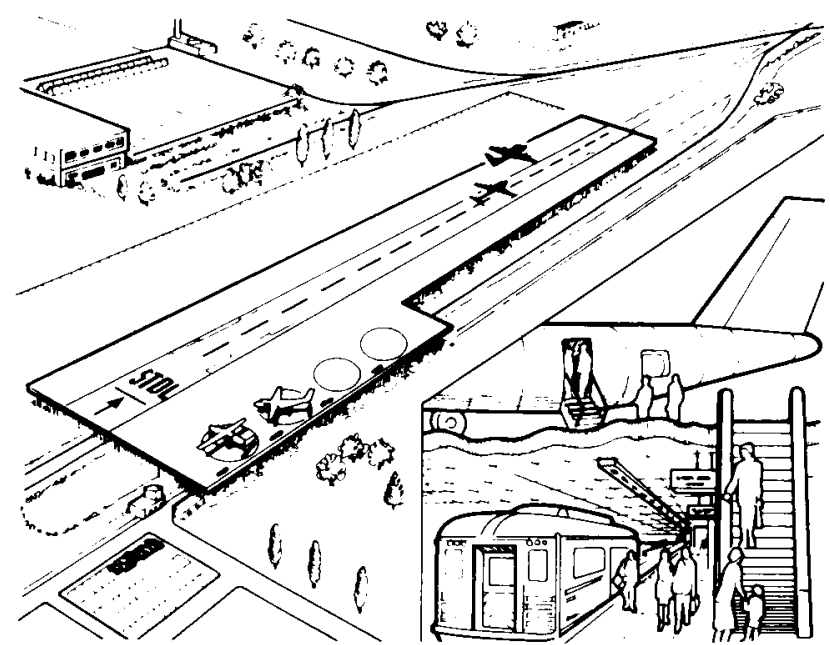

(b) RAILWAY PORT

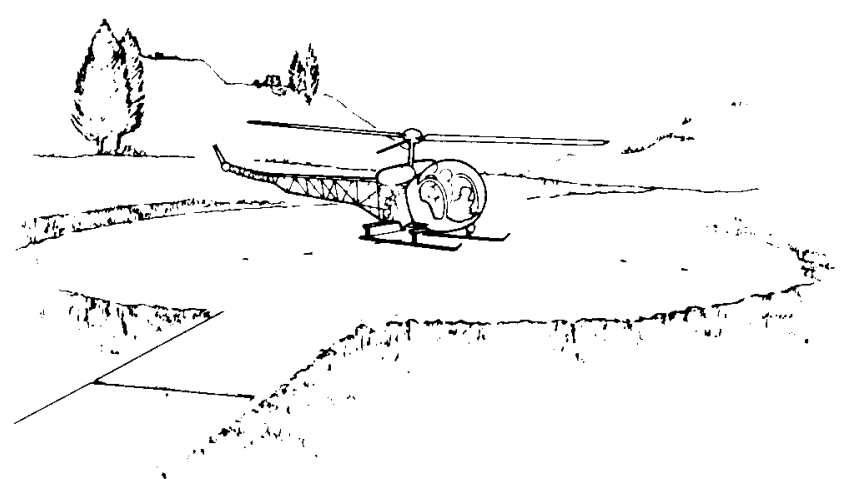

(d) REMOTE HELIPORT

Fig. 4 Potential V/STOL landing facilities.

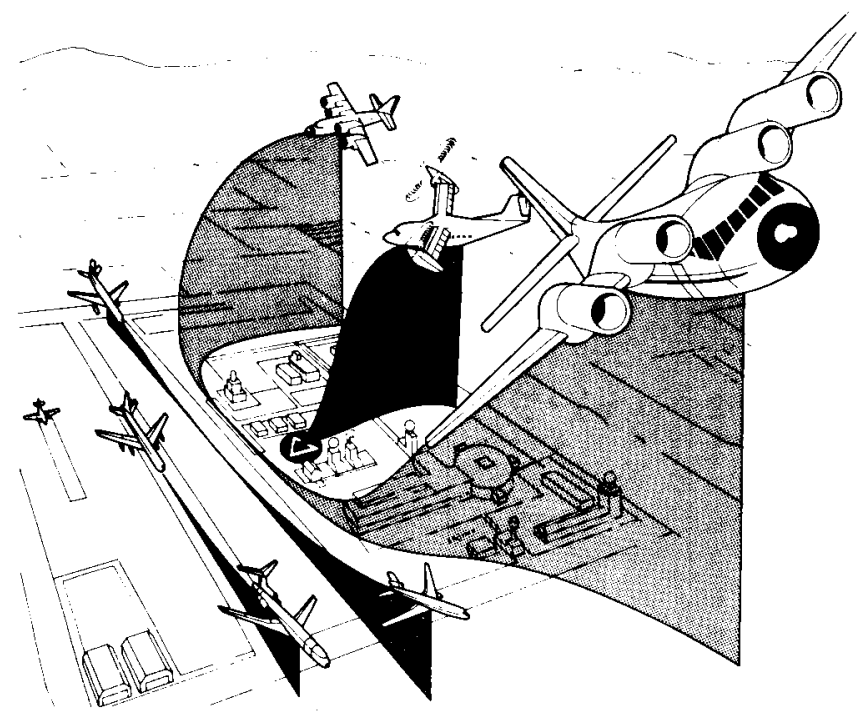

Fig. 5 Airport expanded operations.

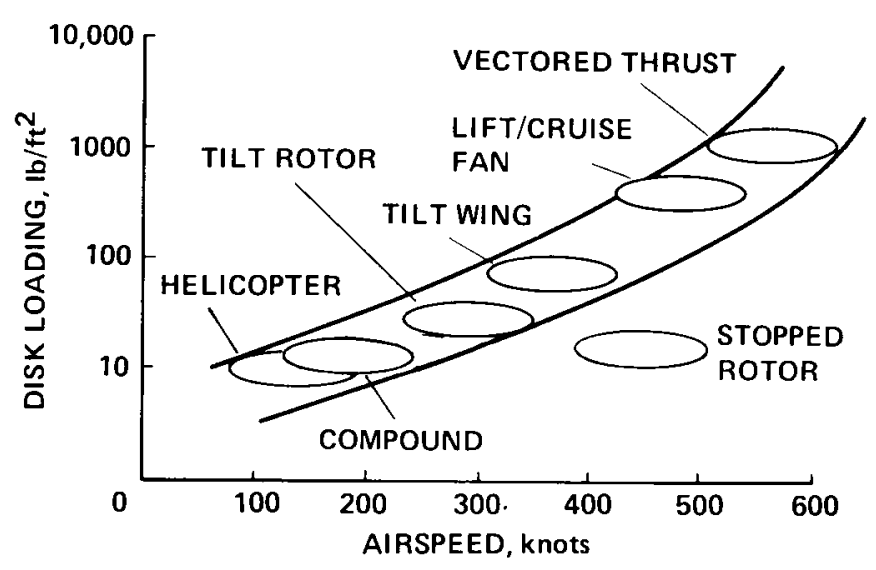

Fig. 6 Disk loading versus speed. 


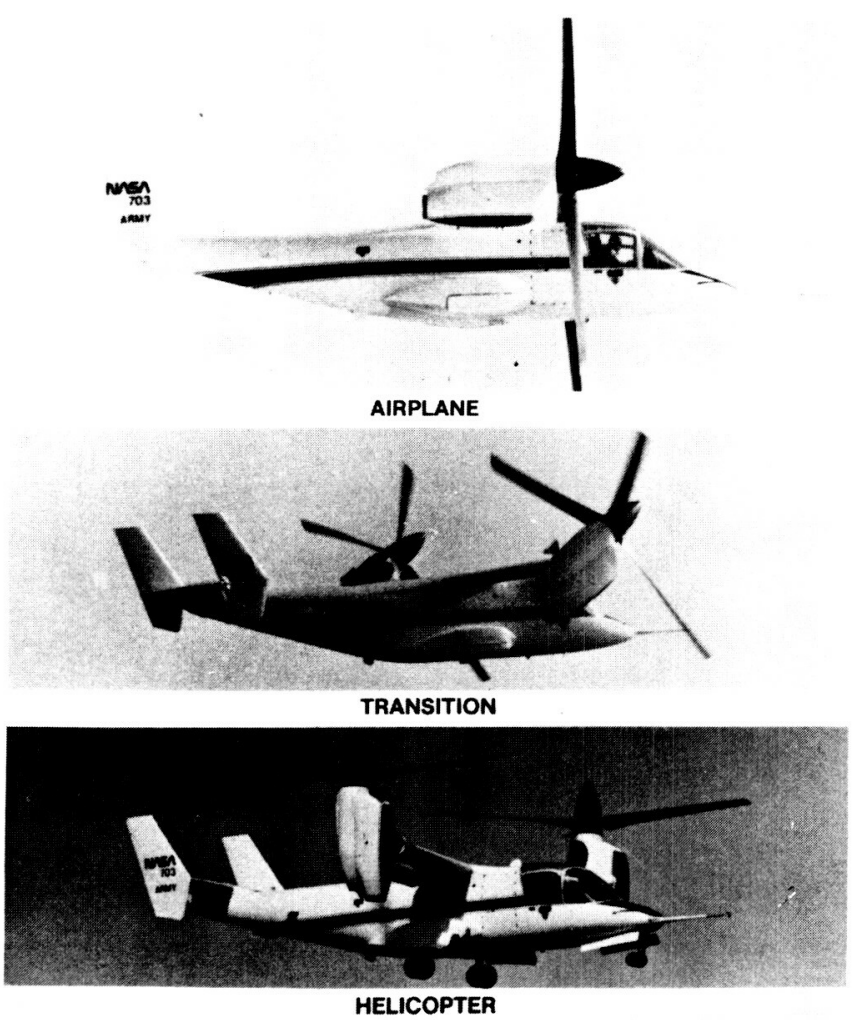

Fig. 7 XV-15 tilt rotor research aircraft.

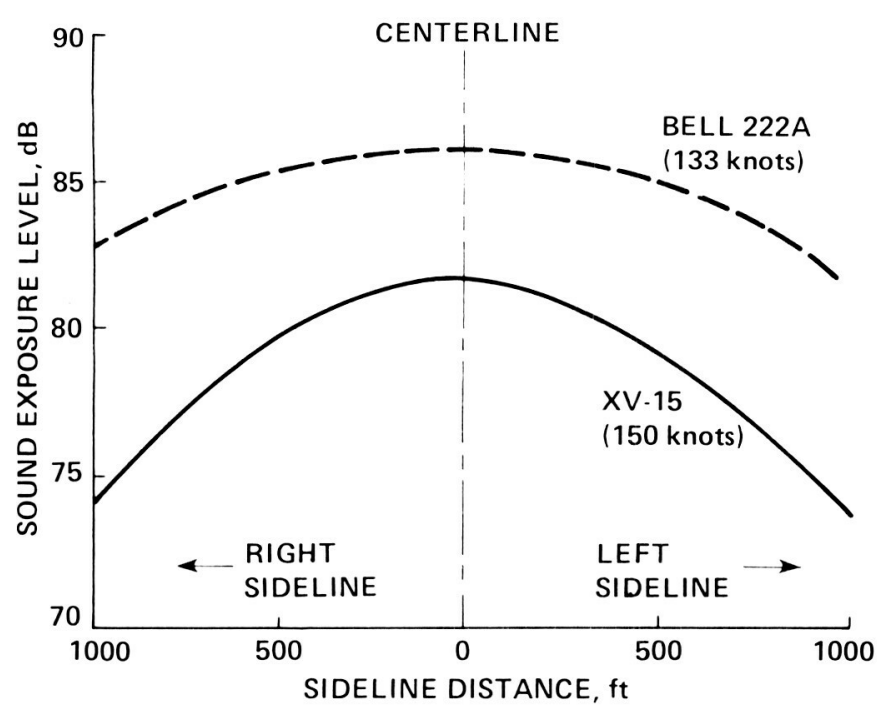

Fig. 9 XV-15 sound-level comparisons.

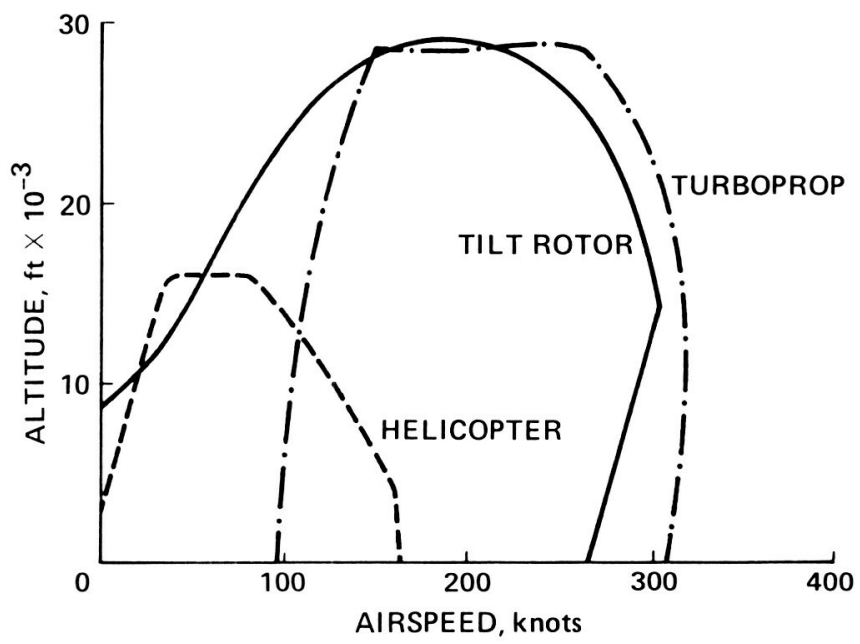

Fig. 8 XV-15 envelope comparison.

ORIGINAC PAGE IS

OF POOR QUALITY

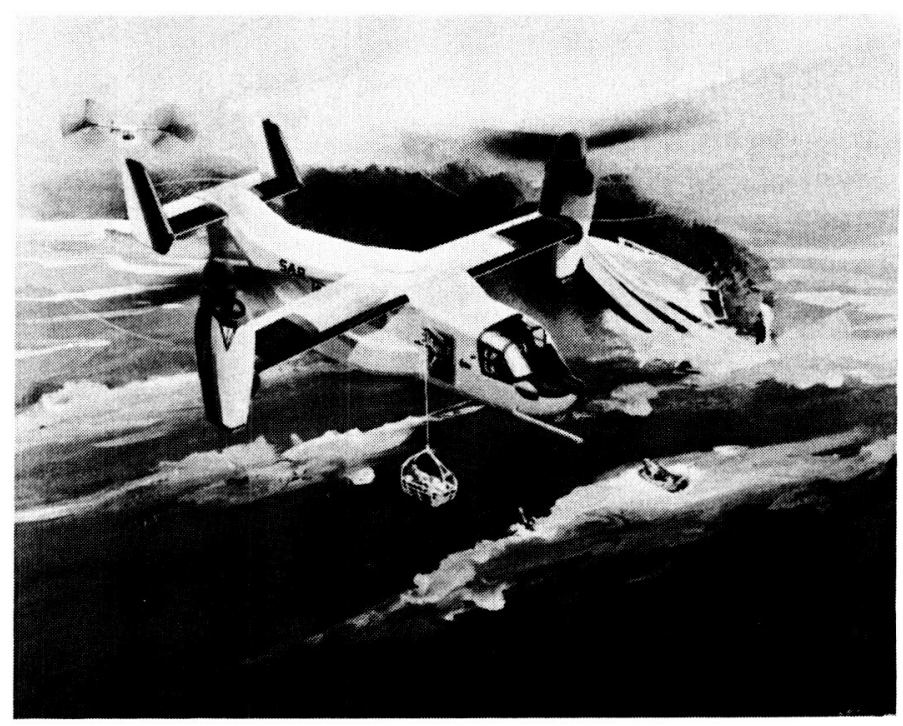

Fig. 10 V-22 aircraft configuration. 
XV-15 SIZE

(8 PASSENGERS)

NEW TILT ROTOR (19 PASSENGERS)

V-22 MIN CHANGE (31 PASSENGERS)

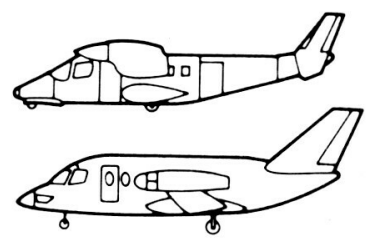

ORIGINAC PAGE IS OF POOR QUALITY

V-22 DERIVATIVE (39 PASSENGERS) NEW FUSELAGE

NEW TILT ROTOR (75 PASSENGERS)
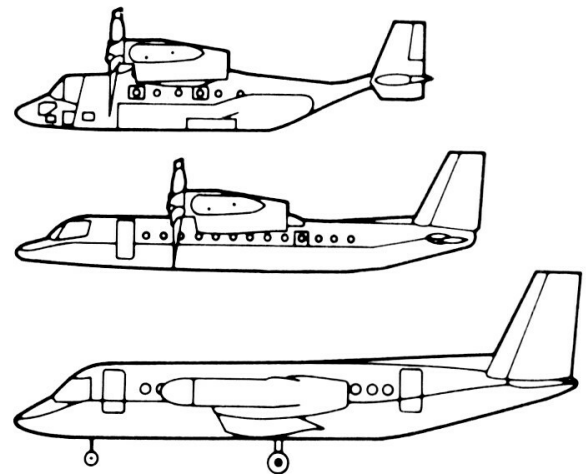

Eig. 11 Civil tilt-rotor configurations.

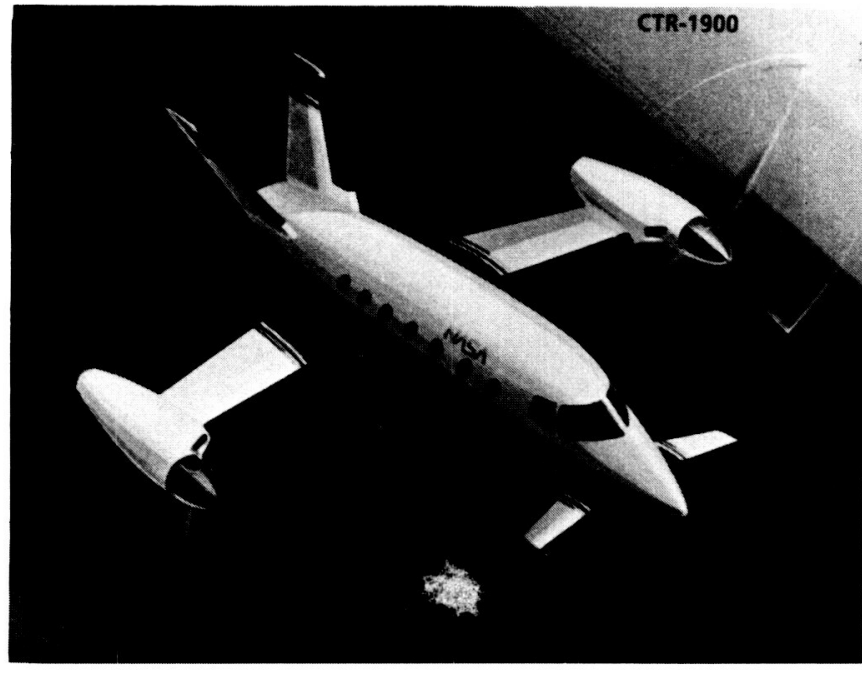

a) 19-passenger;

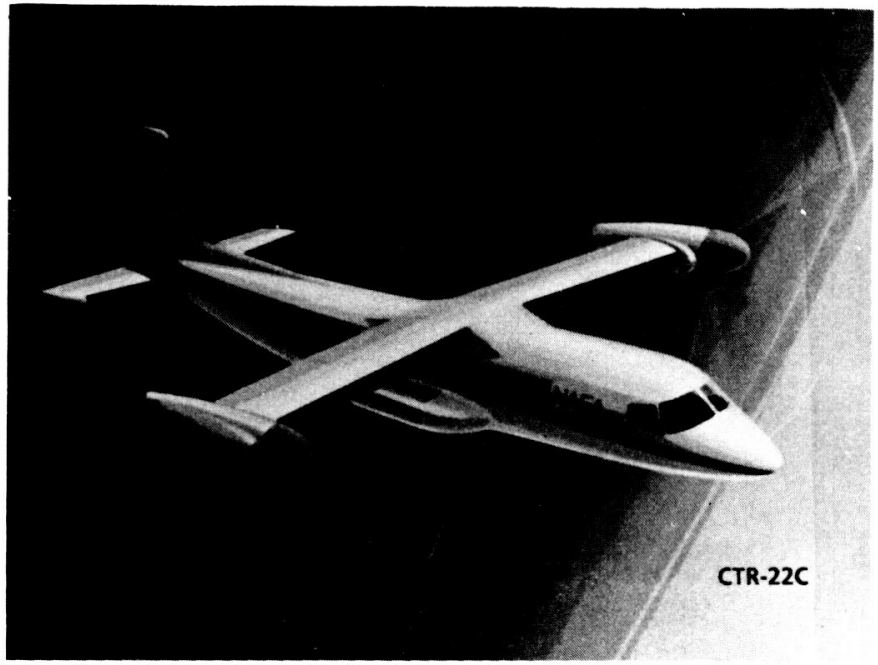

b) 39-passenger.

Fig. 12 Artist concept of civil tilt-rotor configurations.

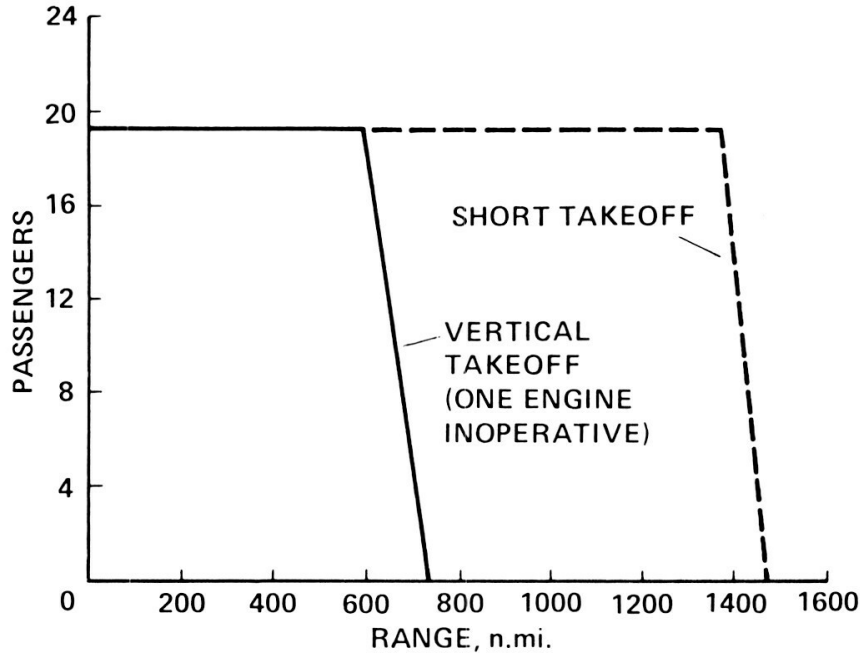

Fig. 13 Payload-range for 19-passenger civil tilt rotor.

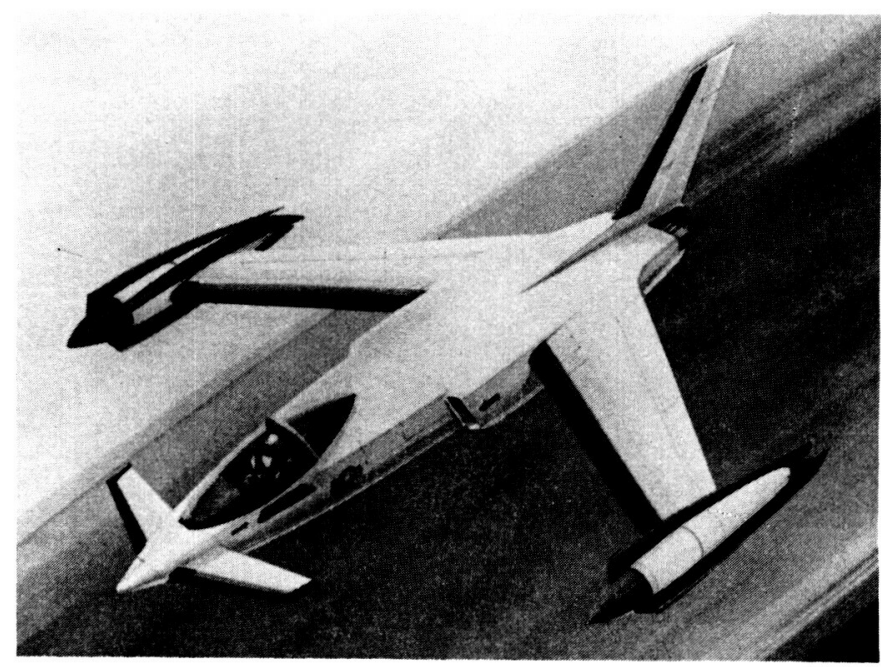

Fig. 14 Folding tilt rotor configuration. 
ORIGINAL PAGE IS
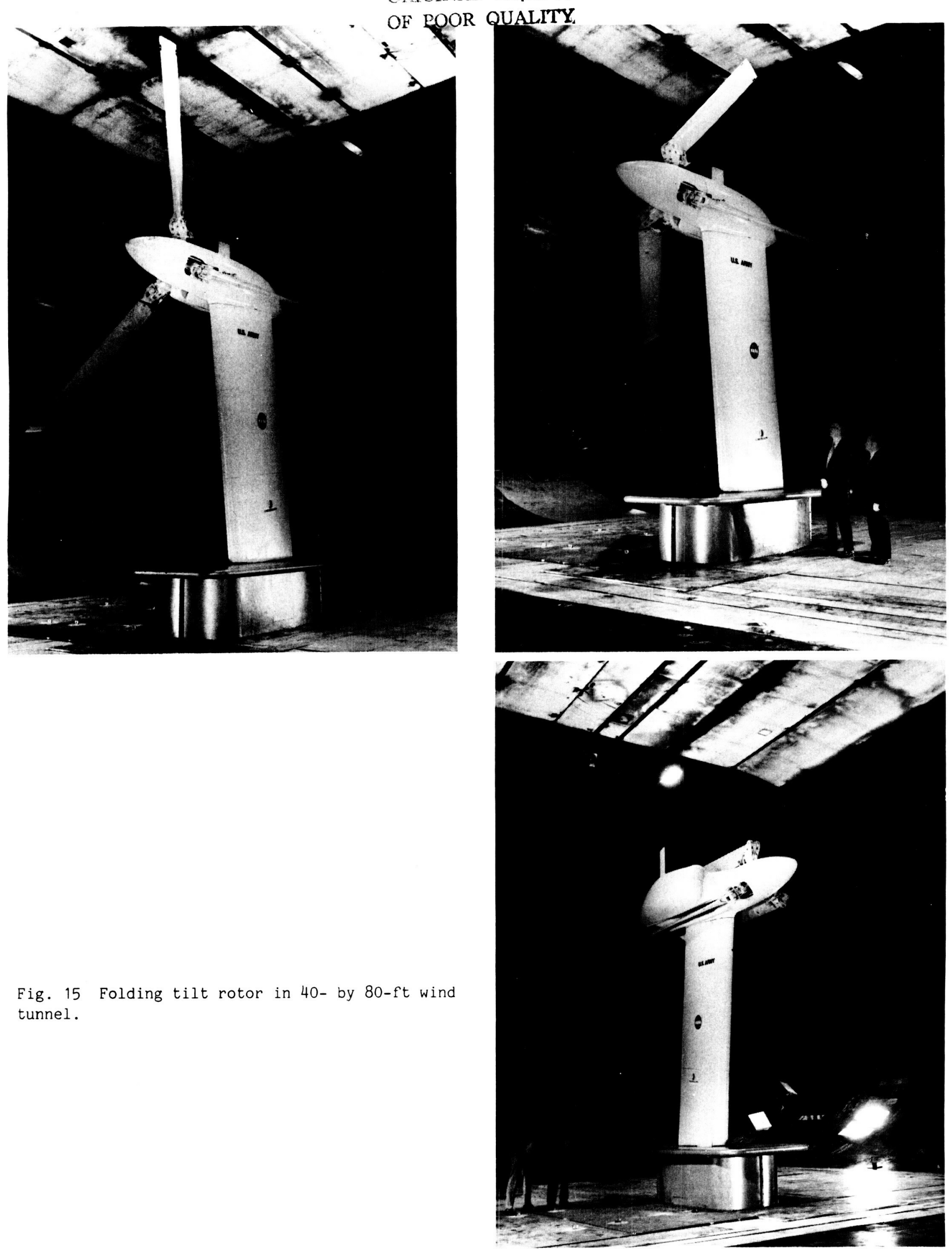

Fig. 15 Folding tilt rotor in $40-$ by $80-\mathrm{ft}$ wind tunnel. 


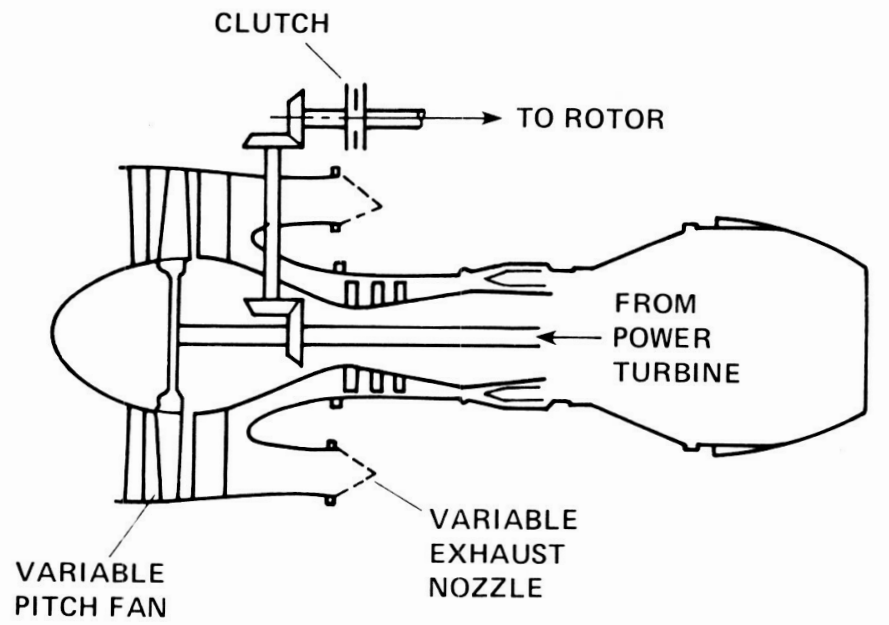

Fig. 16 Convertible engine schematic.

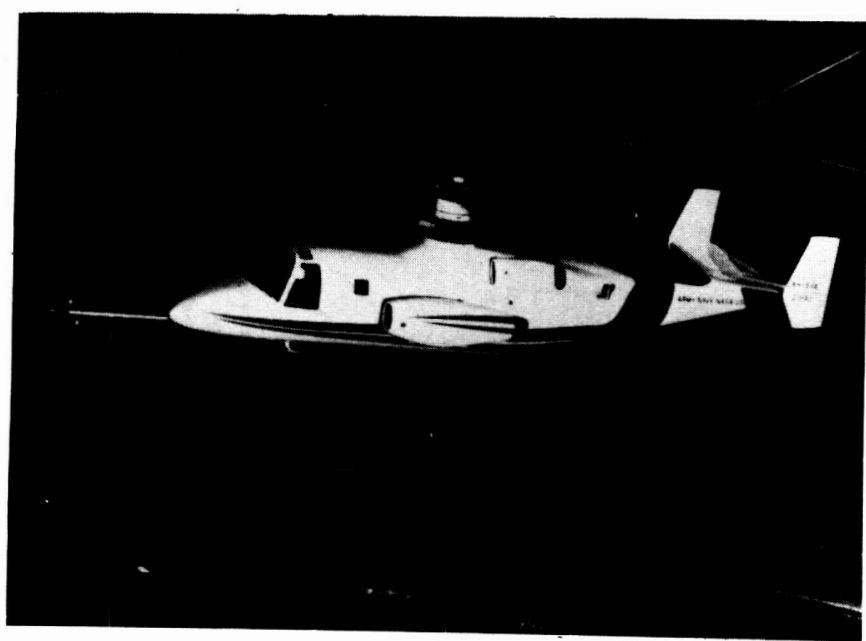

Fig. 18 Compound advancing blade concept ( $A B C$ ) research aircraft.

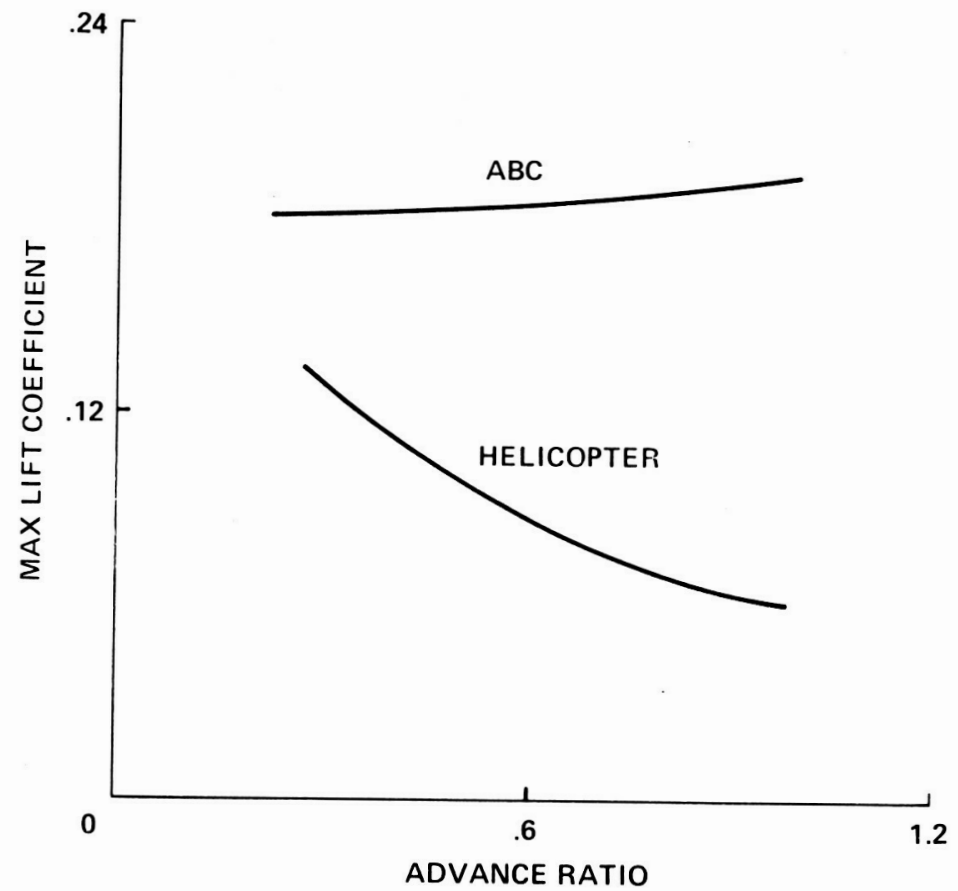

Fig. 17 ABC lift characteristics.

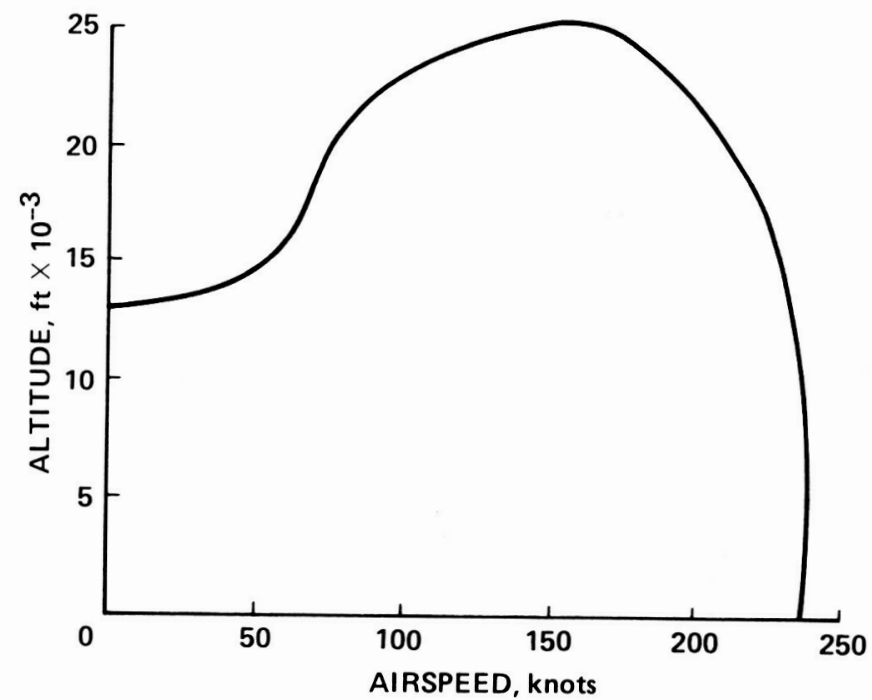

Fig. 19 ABC flight envelope. 


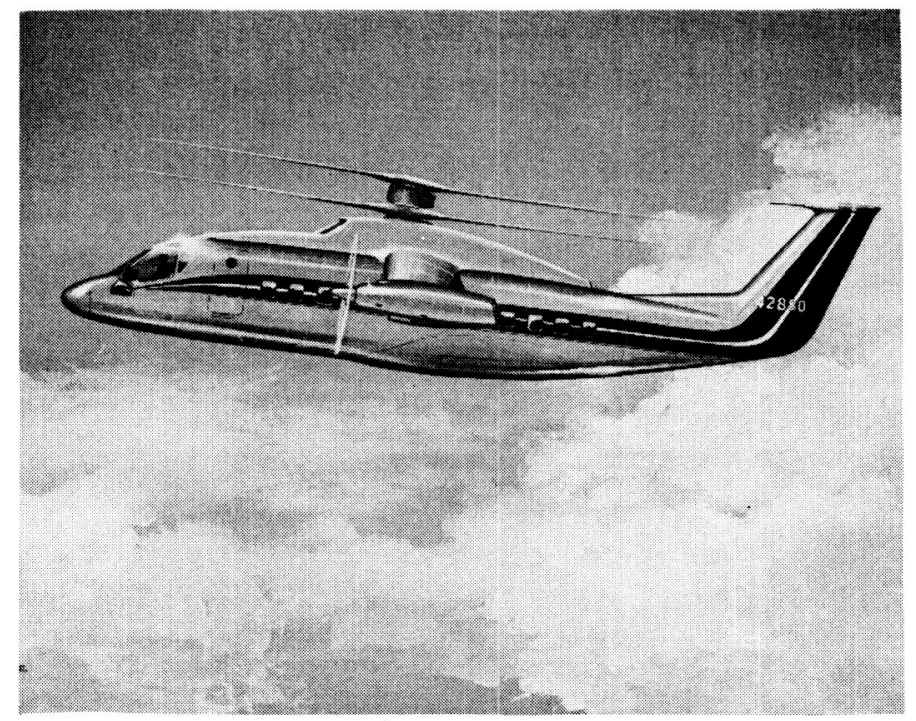

Fig. 20 Compound $A B C$ civil aircraft configuration.

ROTARY-WING MODE

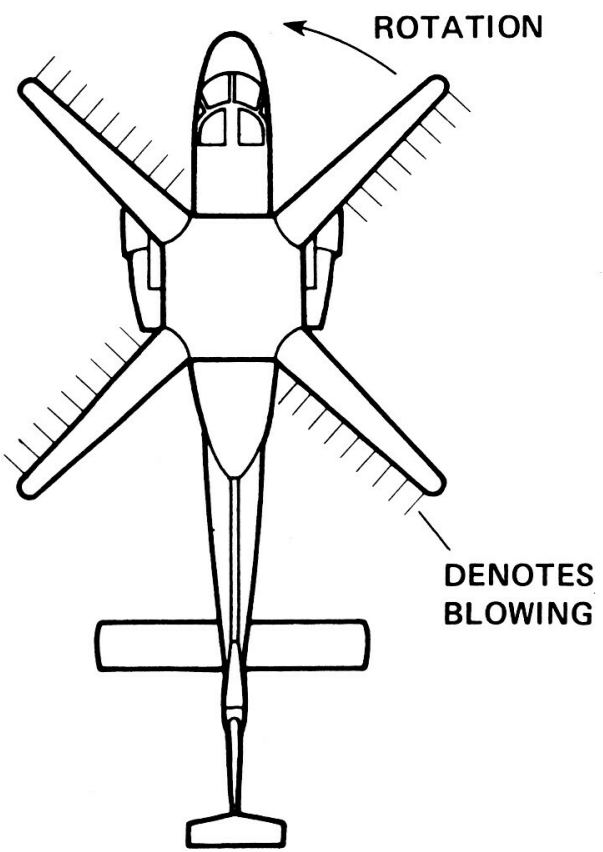

0-150 knots
CONVERSION MODE

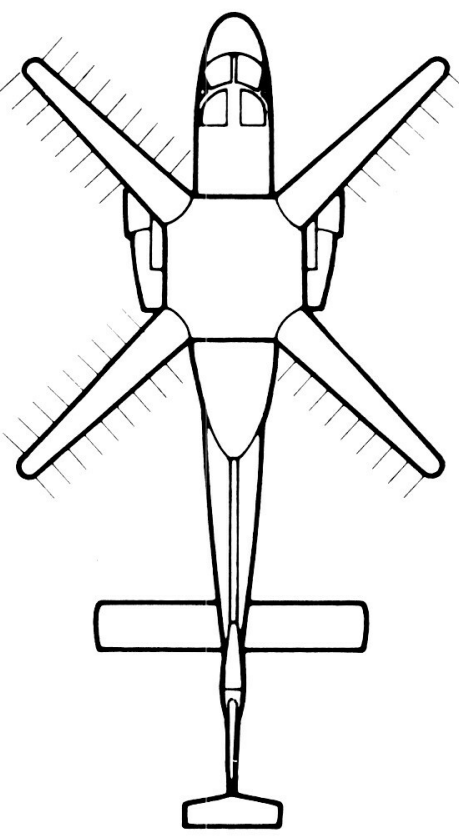

150-200 knots
FIXED-WING MODE

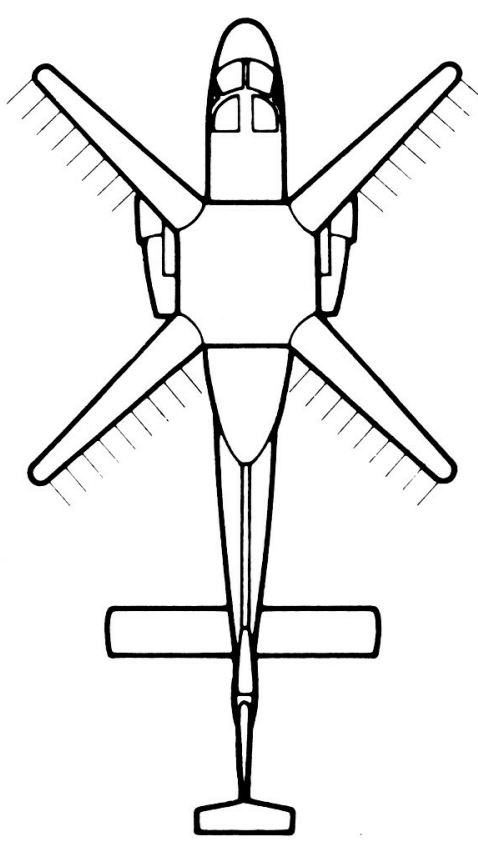

200-500 knots

Fig. $21 \mathrm{X}$-wing flight modes. 


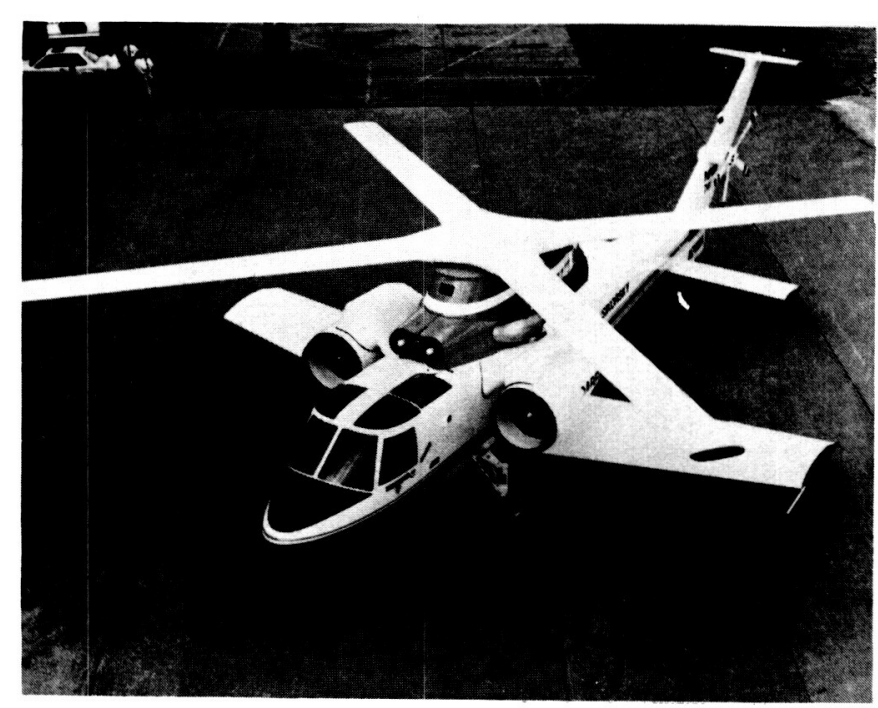

Fig. 22 RSRA/X-wing aircraft.

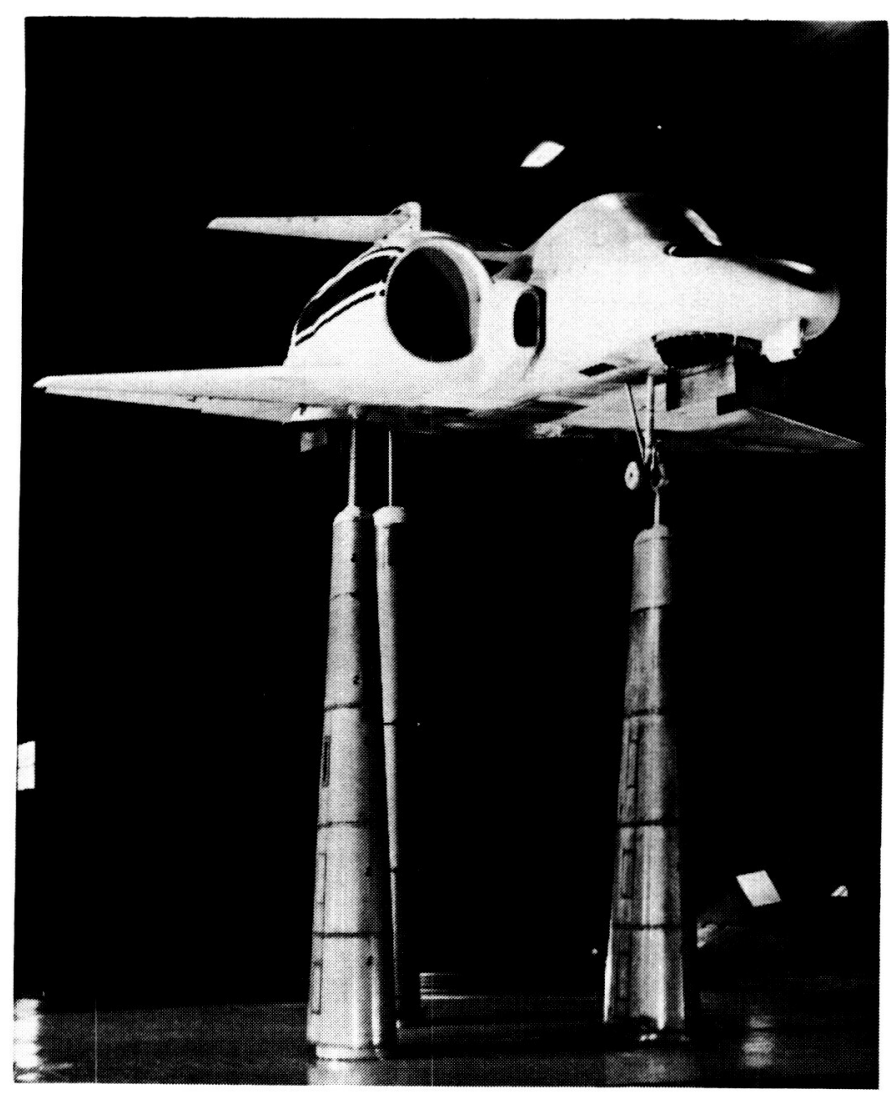

ORJGINAI PAGE IS

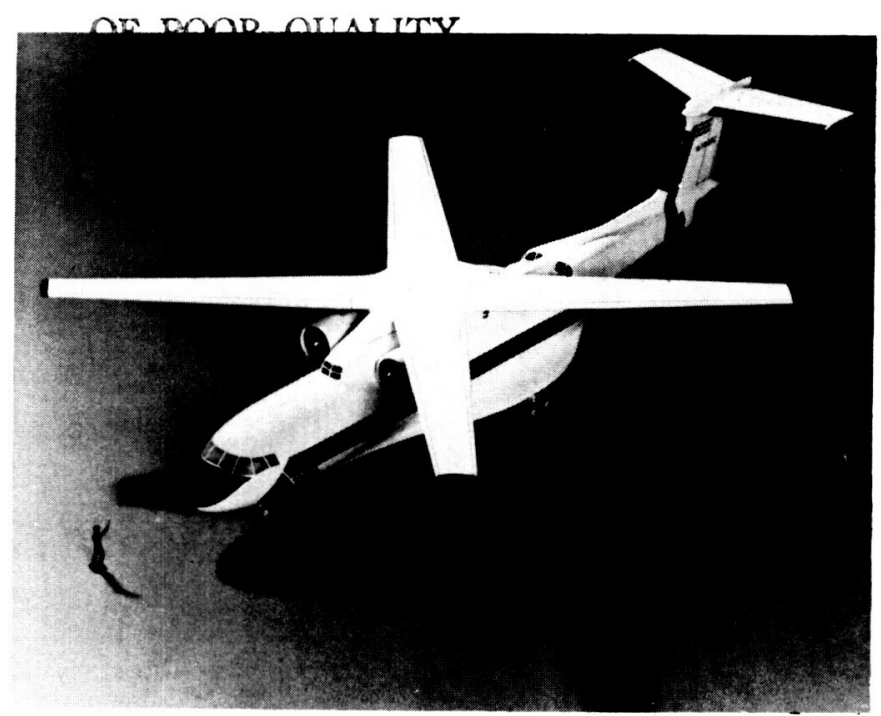

Fig. $23 \mathrm{X}$-wing civil aircraft configuration.

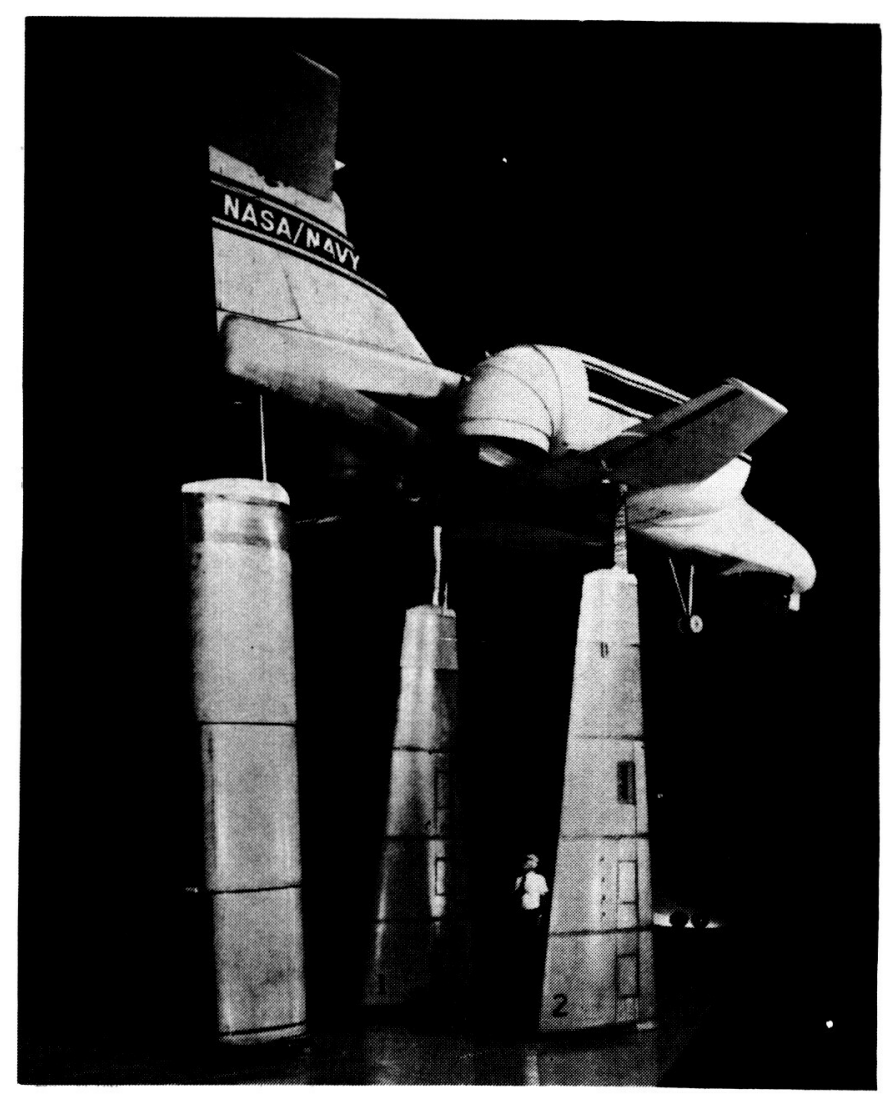

Fig. 24 Lift-cruise fan full-scale model. 


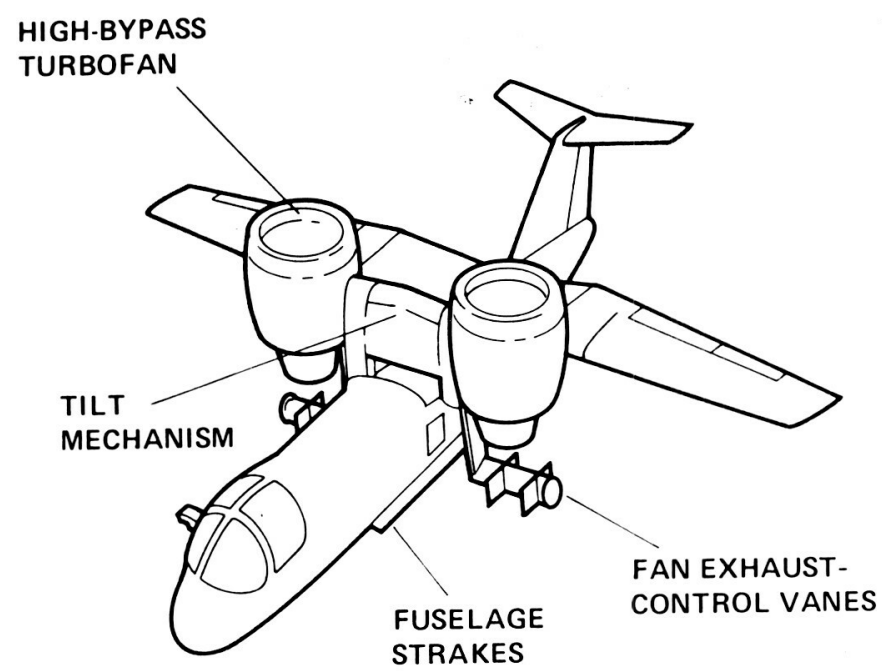

Fig. 25 Tilt nacelle aircraft schematic.

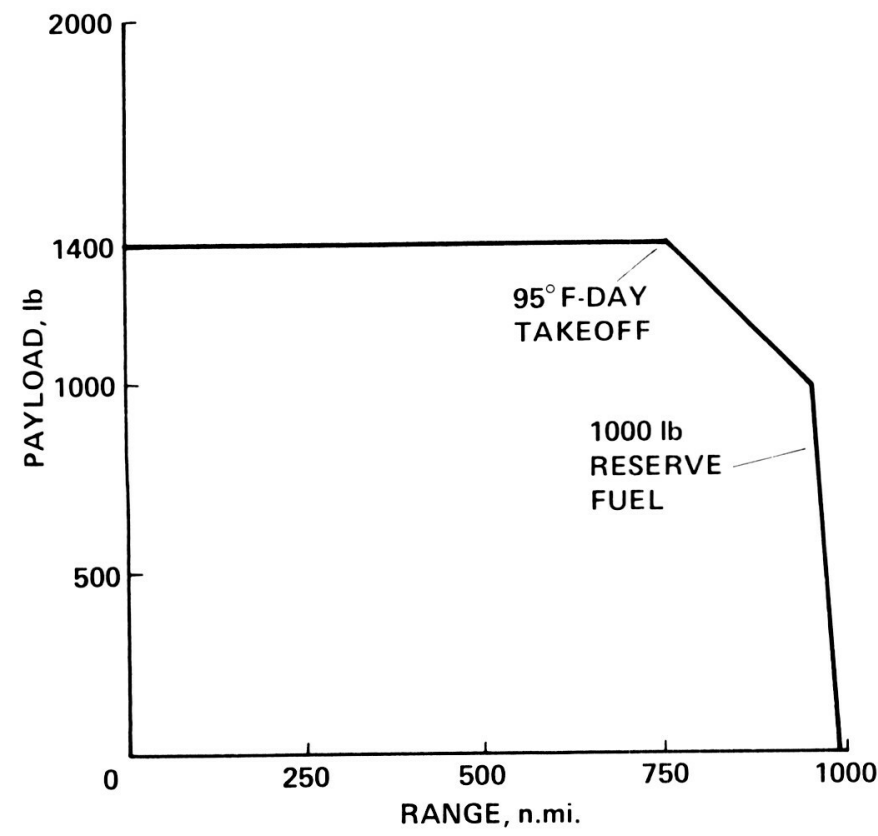

Fig. 27 Tilt nacelle payload-range.

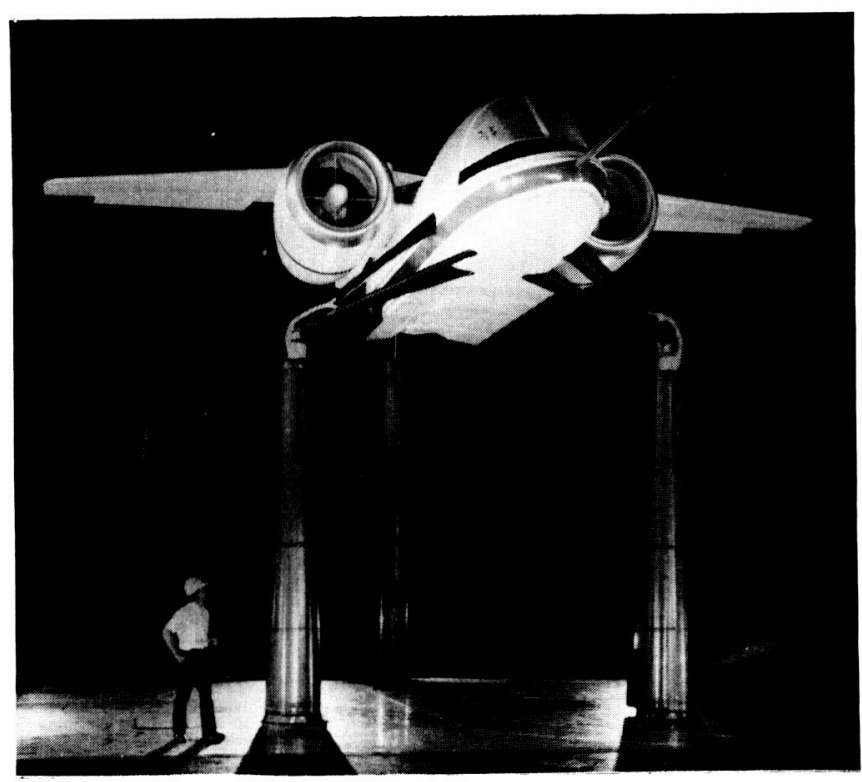

Fig. 26 Tilt nacelle full-scale model.

ORIGINAL PAGE TS

OF POOR QUALTY

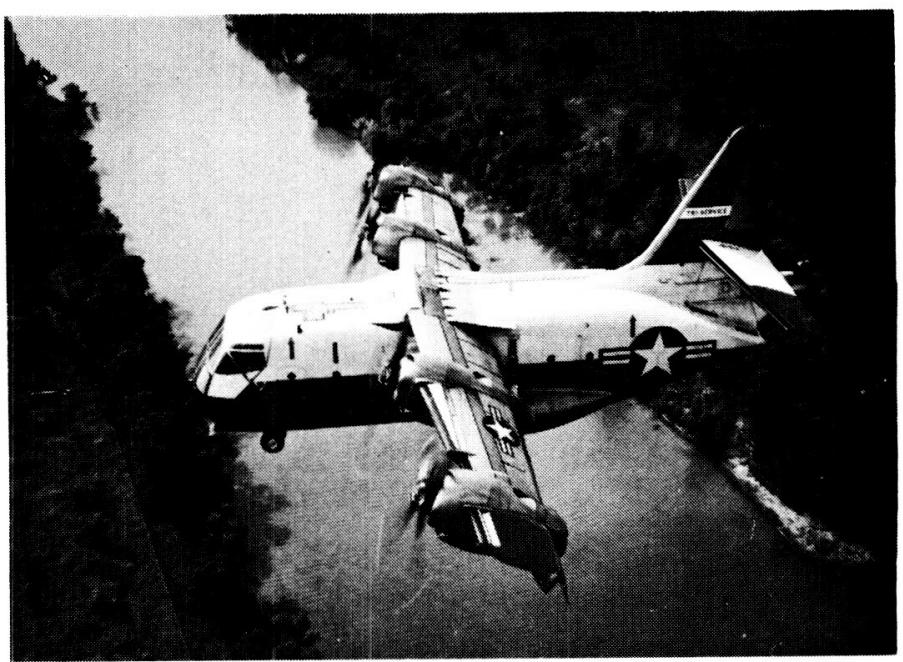

Fig. 28 Tilt wing research aircraft (XC-142A). 
TAIL-PROPELLER

SHAFTING

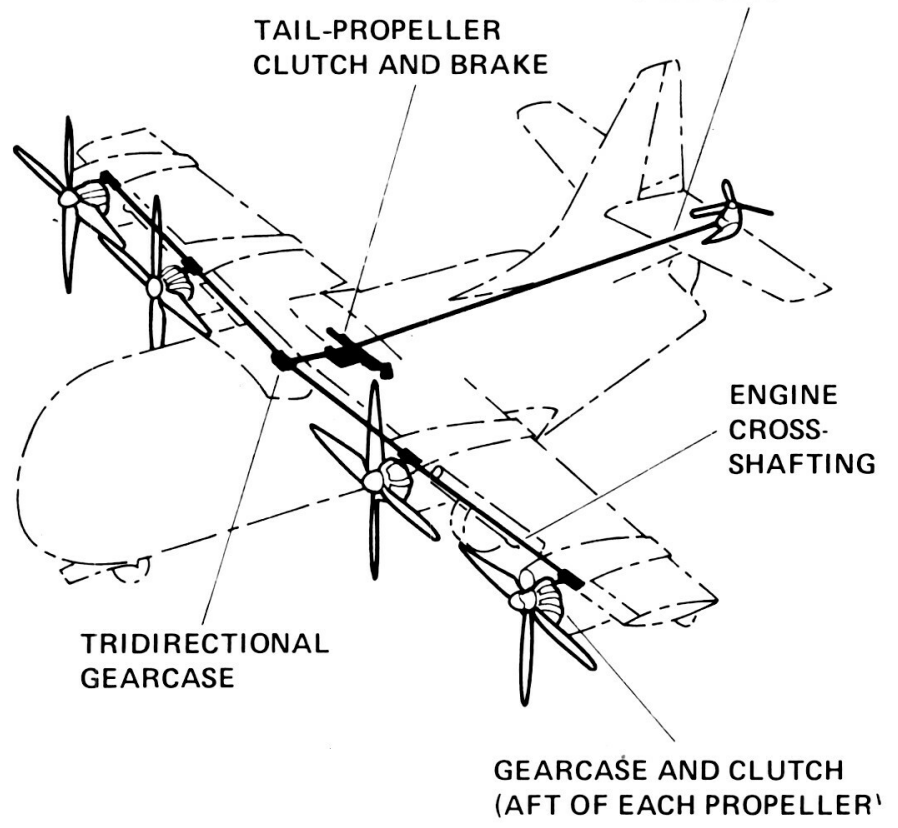

Fig. 29 Tilt wing aircraft schematic.

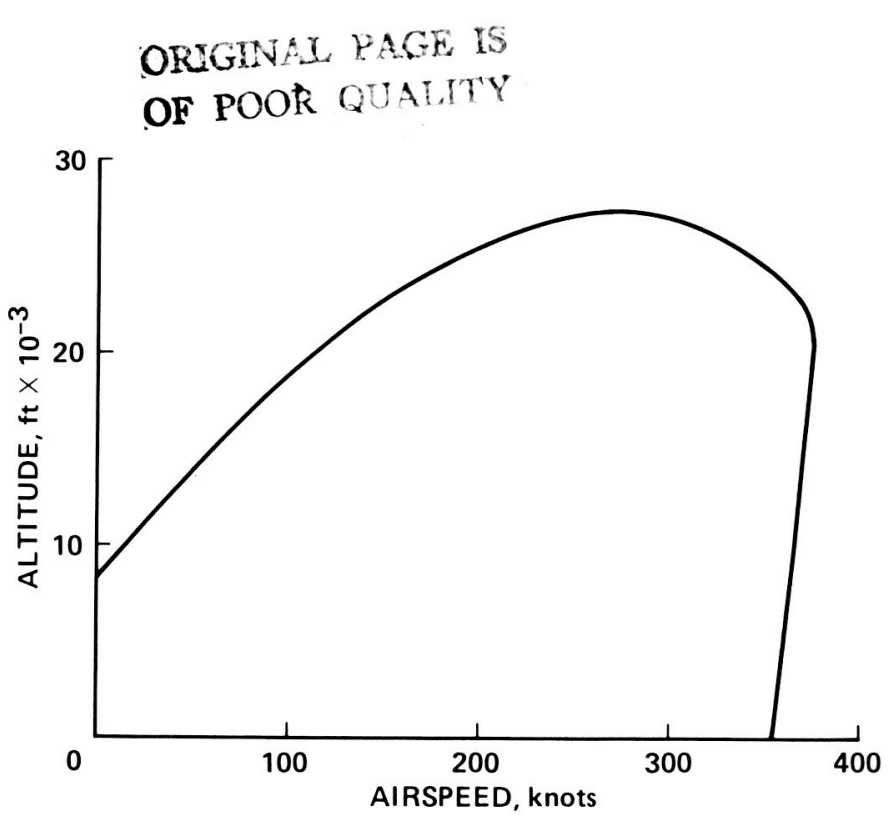

Fig. 30 Tilt wing flight envelope.

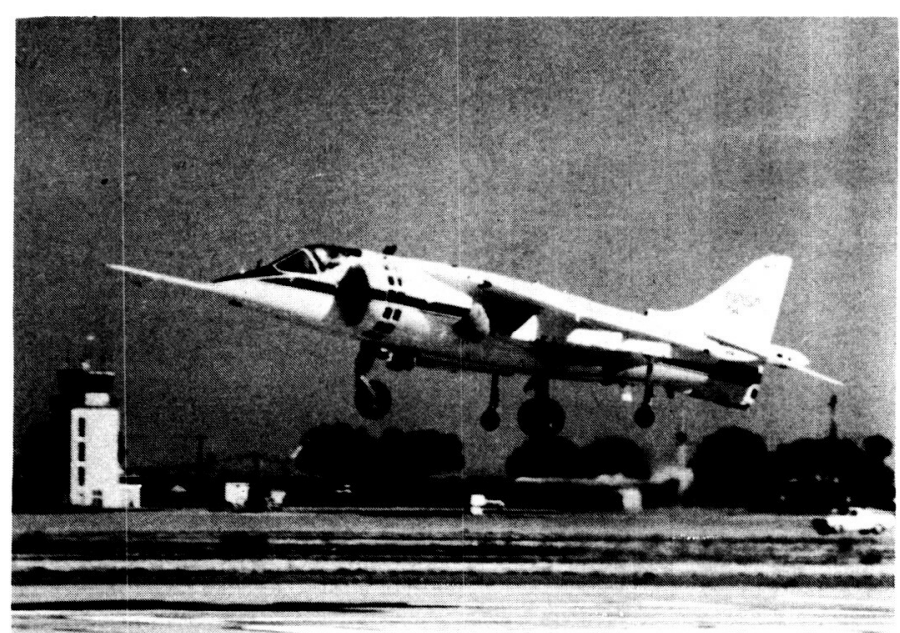

Fig. 31 V/STOL research aircraft (YAV-8B).

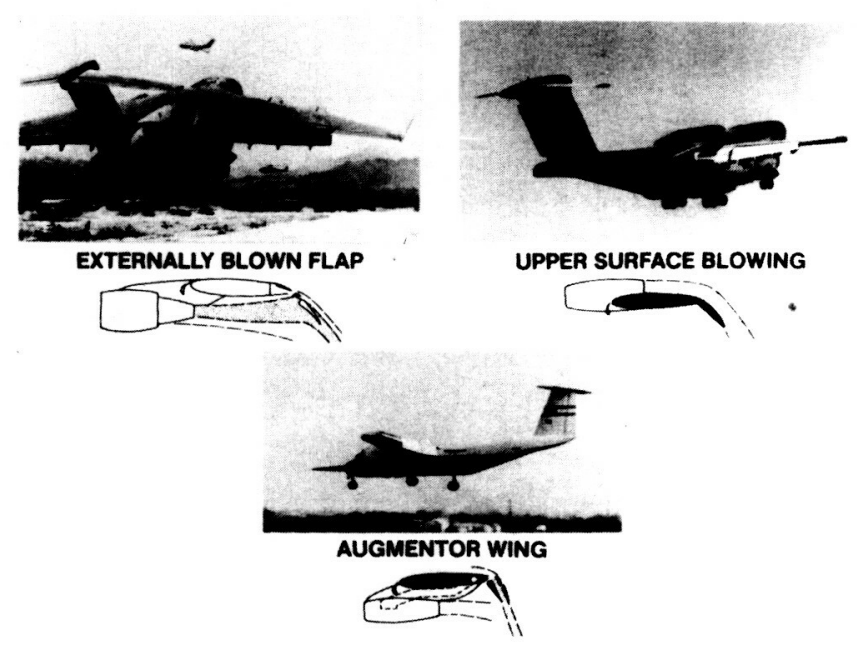

Fig. 32 High-speed STOL designs. 
EXHAUST AIR TURNING

DUE TO COANDA EFFECT

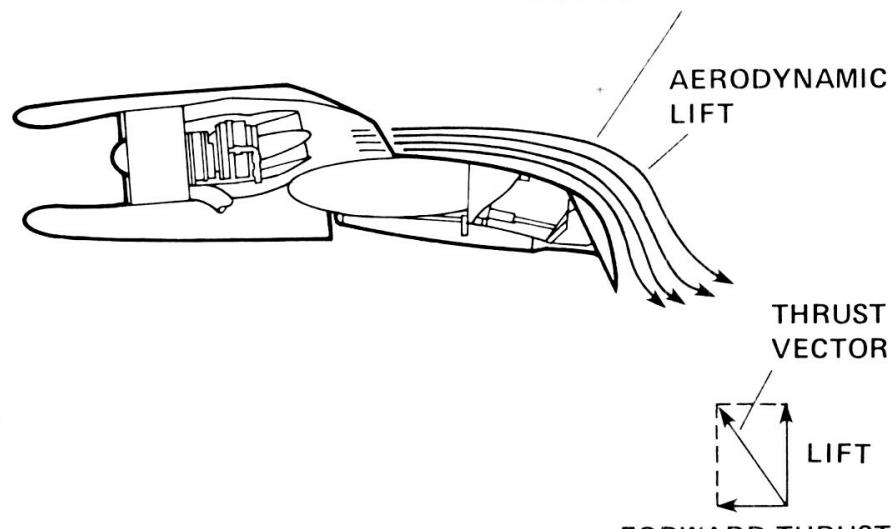

FORWARD THRUST

Fig. 33 Upper surface blowing.

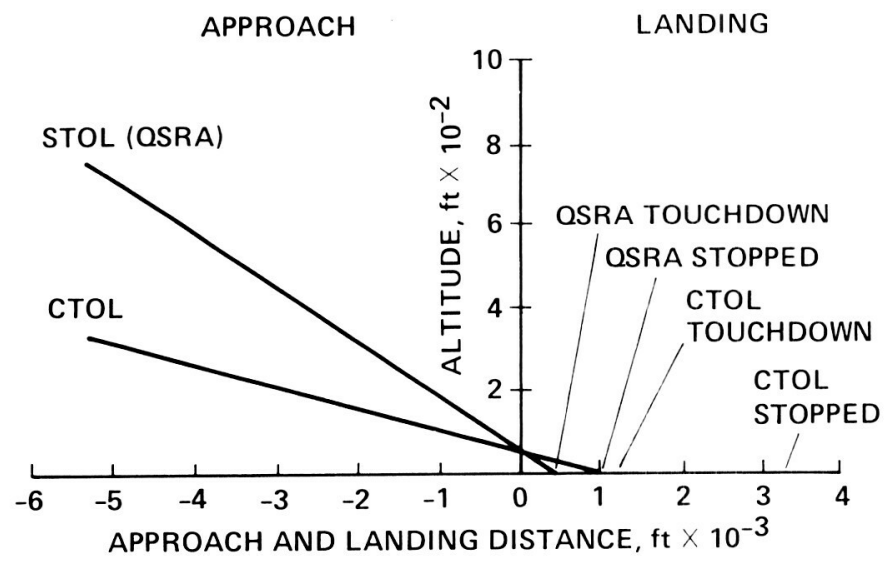

Fig. 35 Landing performance.

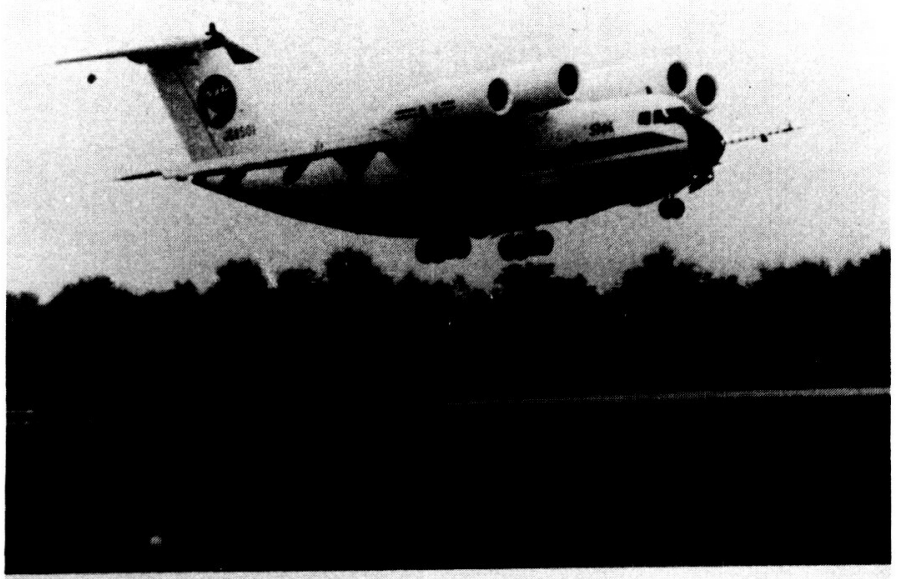

Fig. 37 Asuka aircraft.

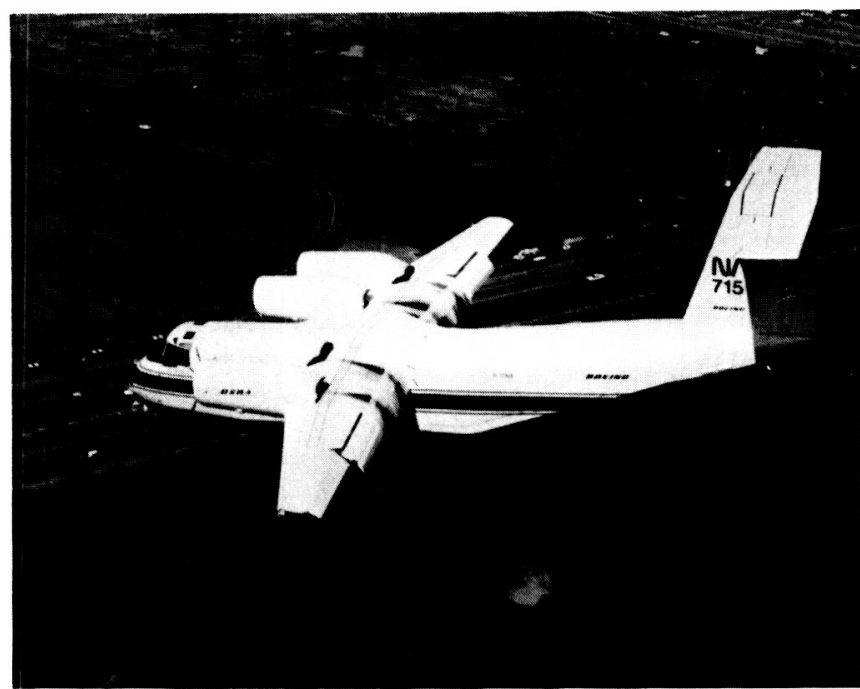

Fig. 34 Quiet STOL Research Aircraft (QSRA).

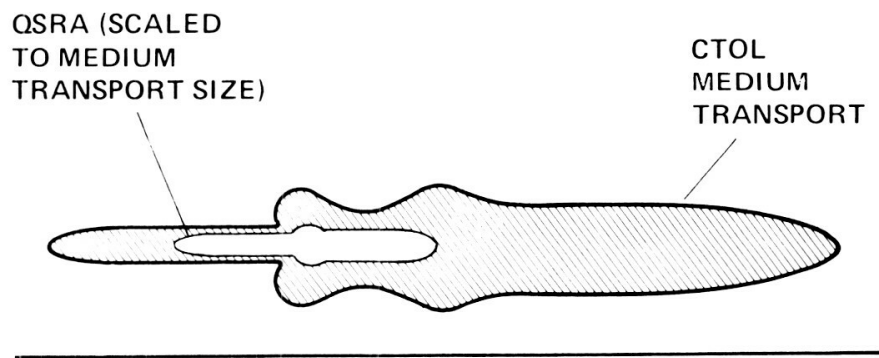

90-EPNdB FOOTPRINTS

Fig. 36 Noise footprints comparison.

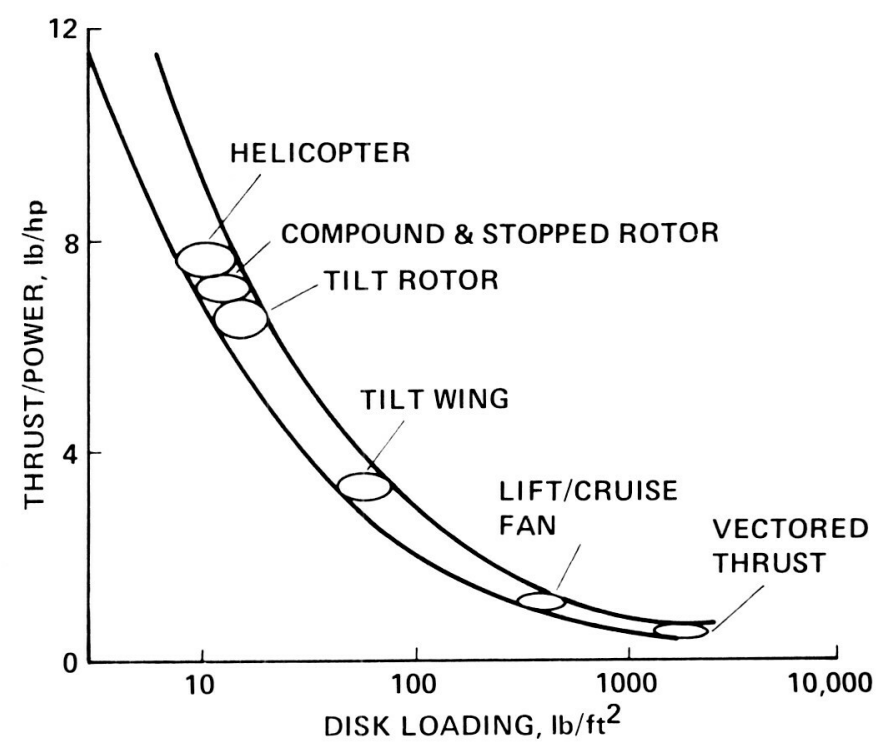

Fig. 38 Hover efficiency comparison. 


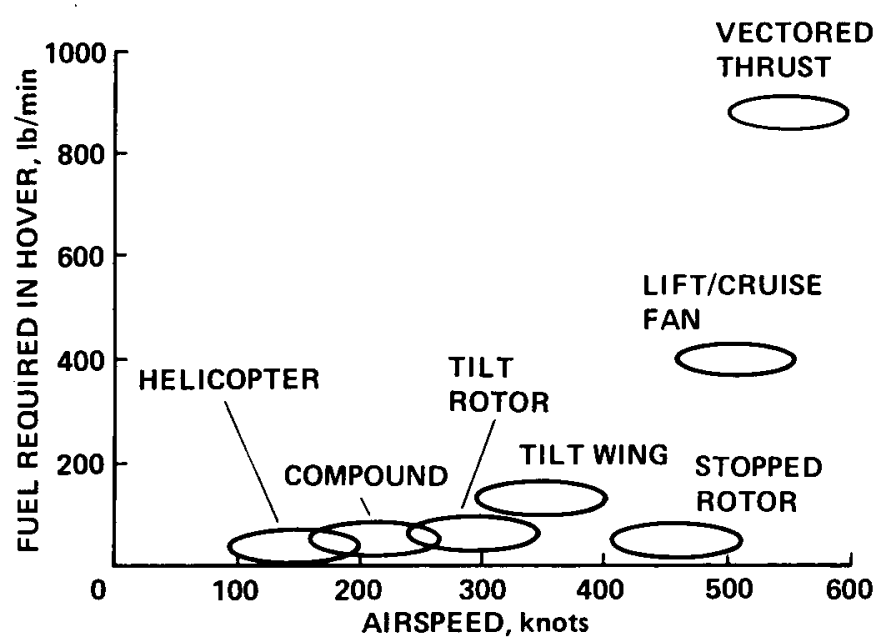

Fig. 39 Fuel required in hover.

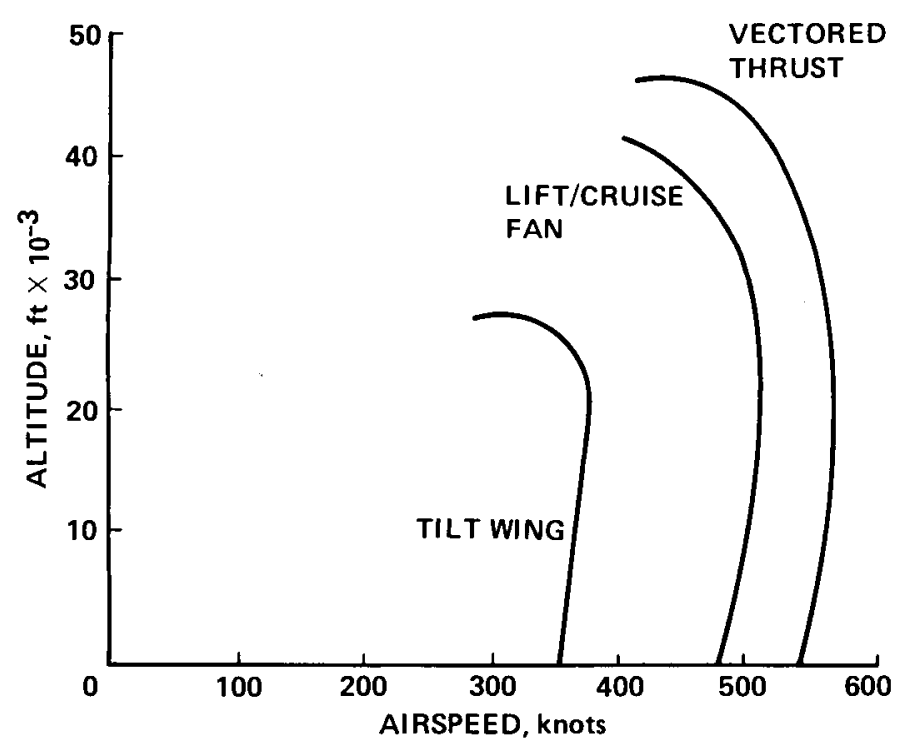

Fig. 41 Flight envelopes of high-disk loading aircraft.

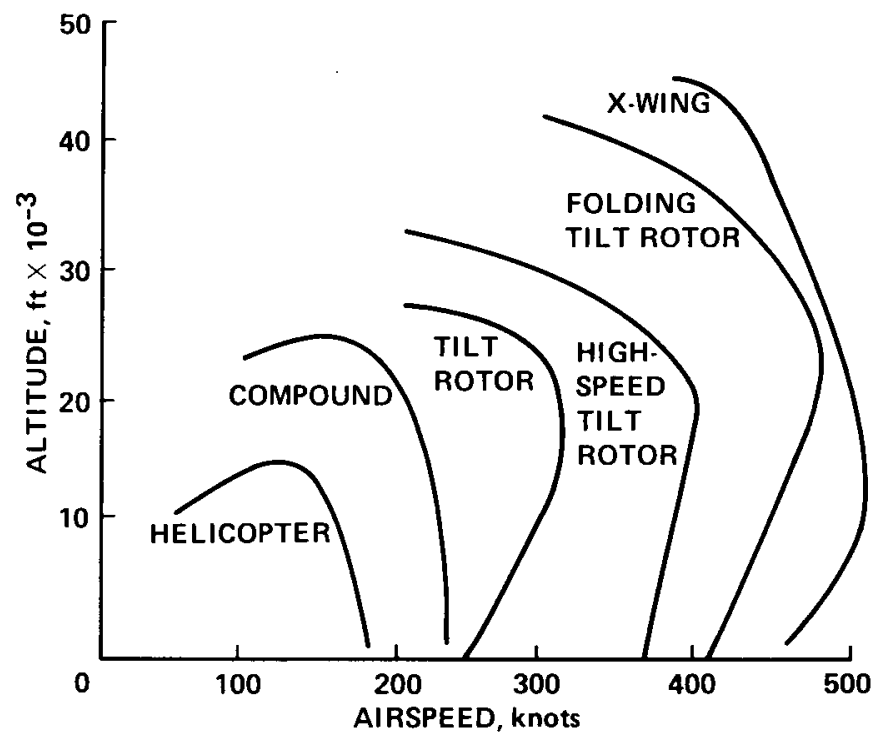

Fig. 40 Flight envelopes of low-disk loading aircraft.

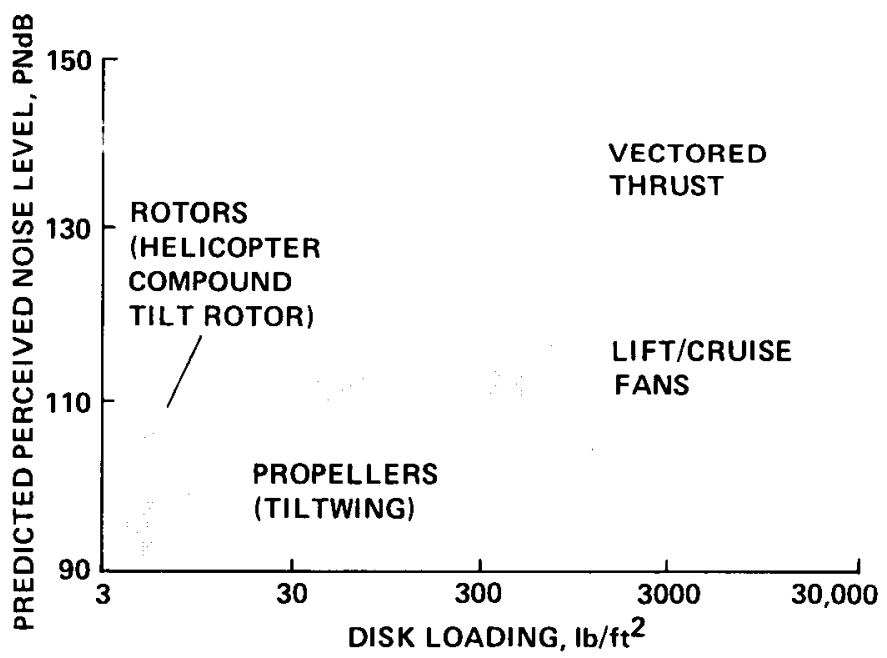

Fig. 42 Noise comparisons. 


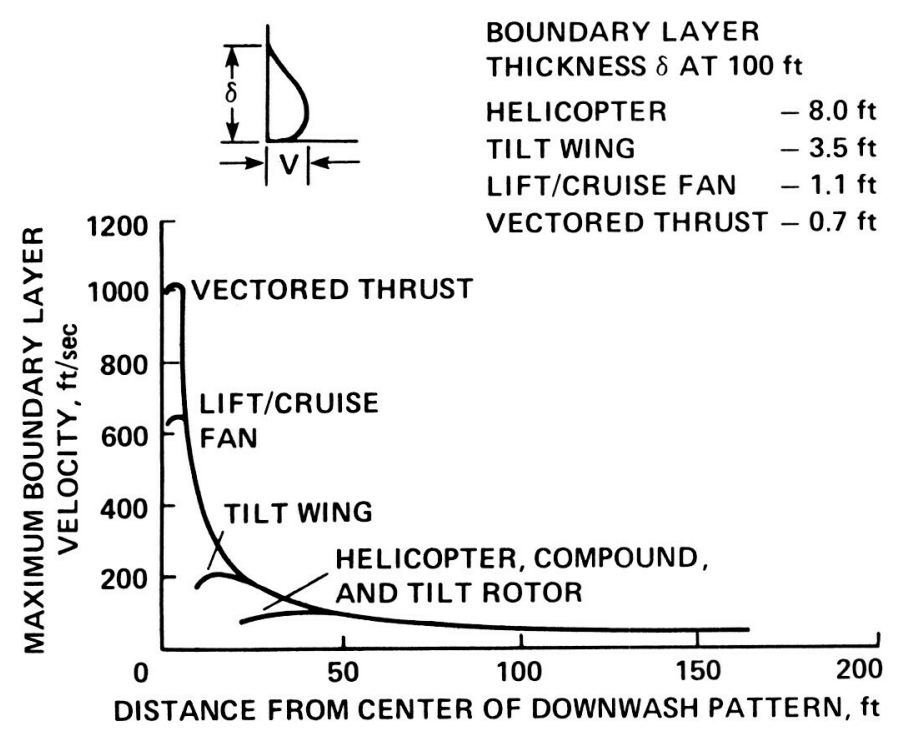

Fig. 43 Downwash comparisons.

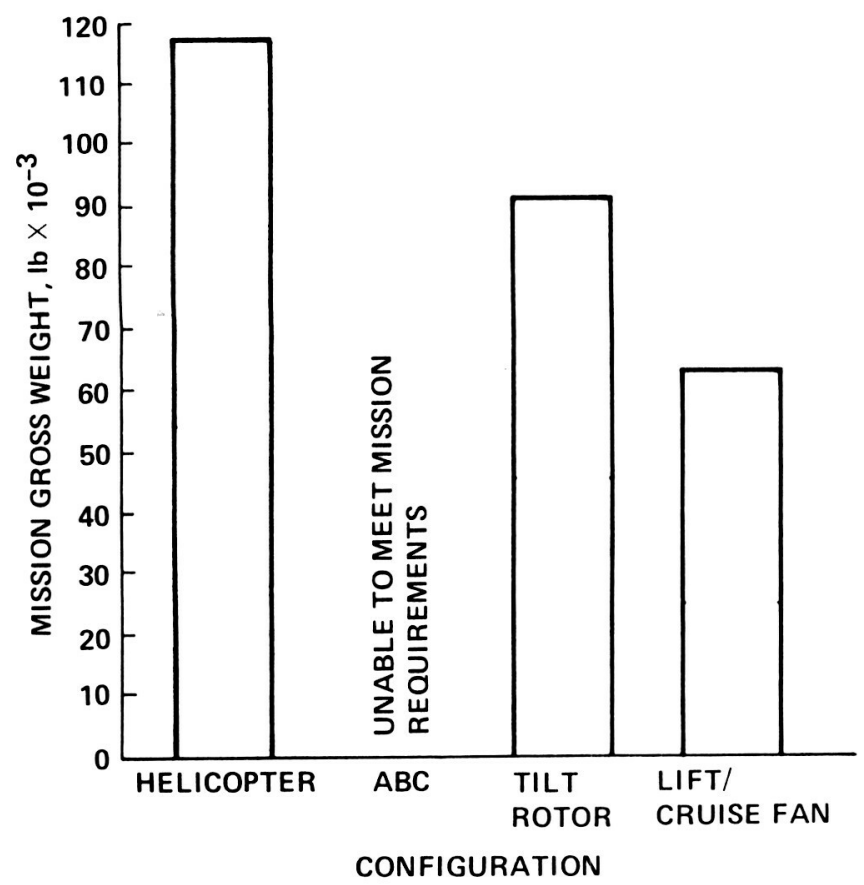

Fig. 45 Analysis comparison for 800-mile transport mission.

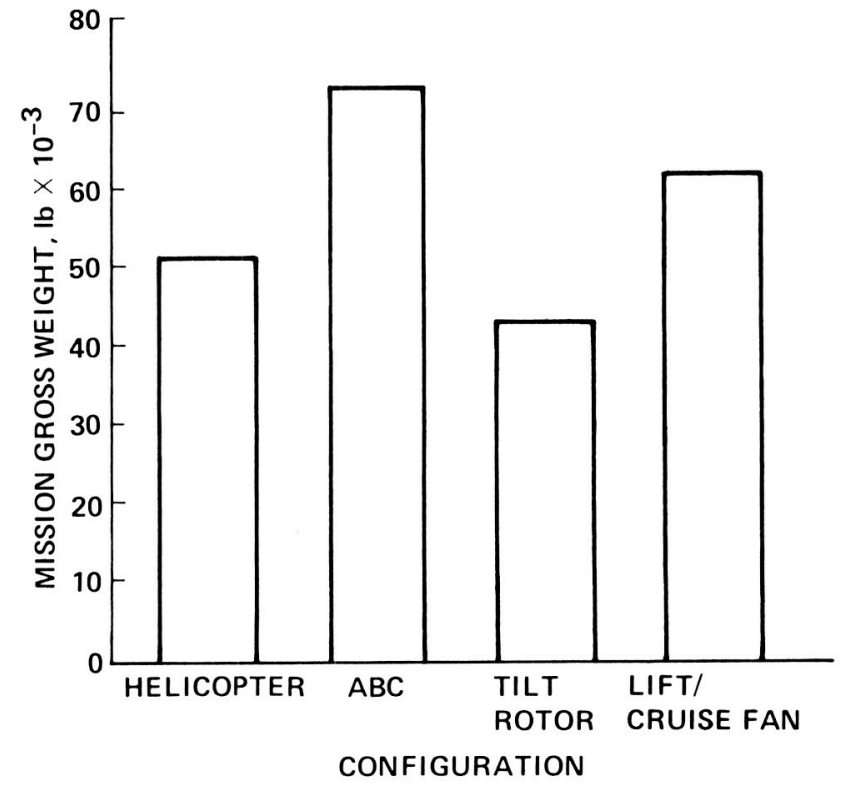

Fig. 44 Analysis comparison for 300-mile search and rescue mission.

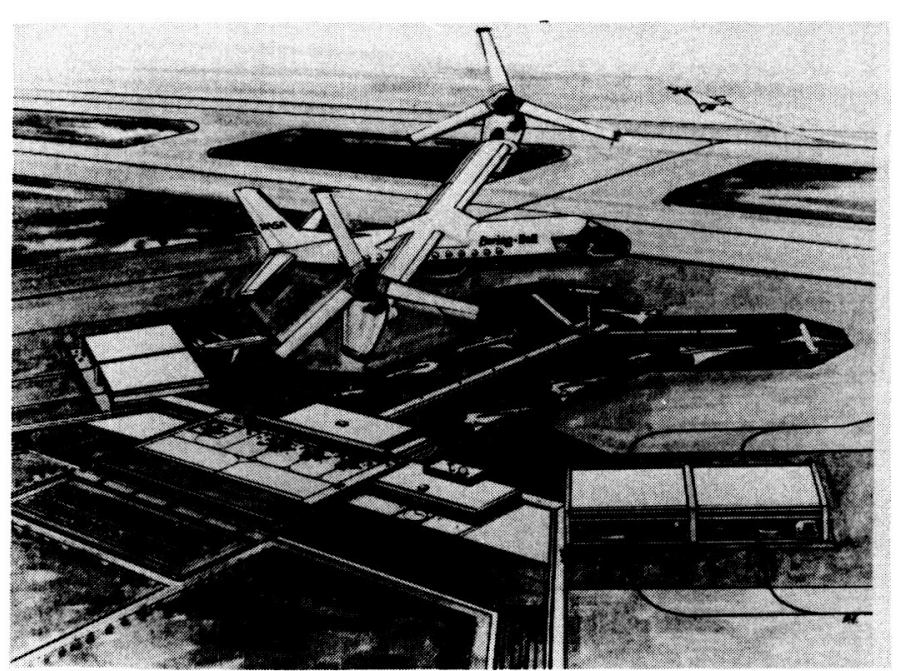

Fig. 46 Airport of the future. 


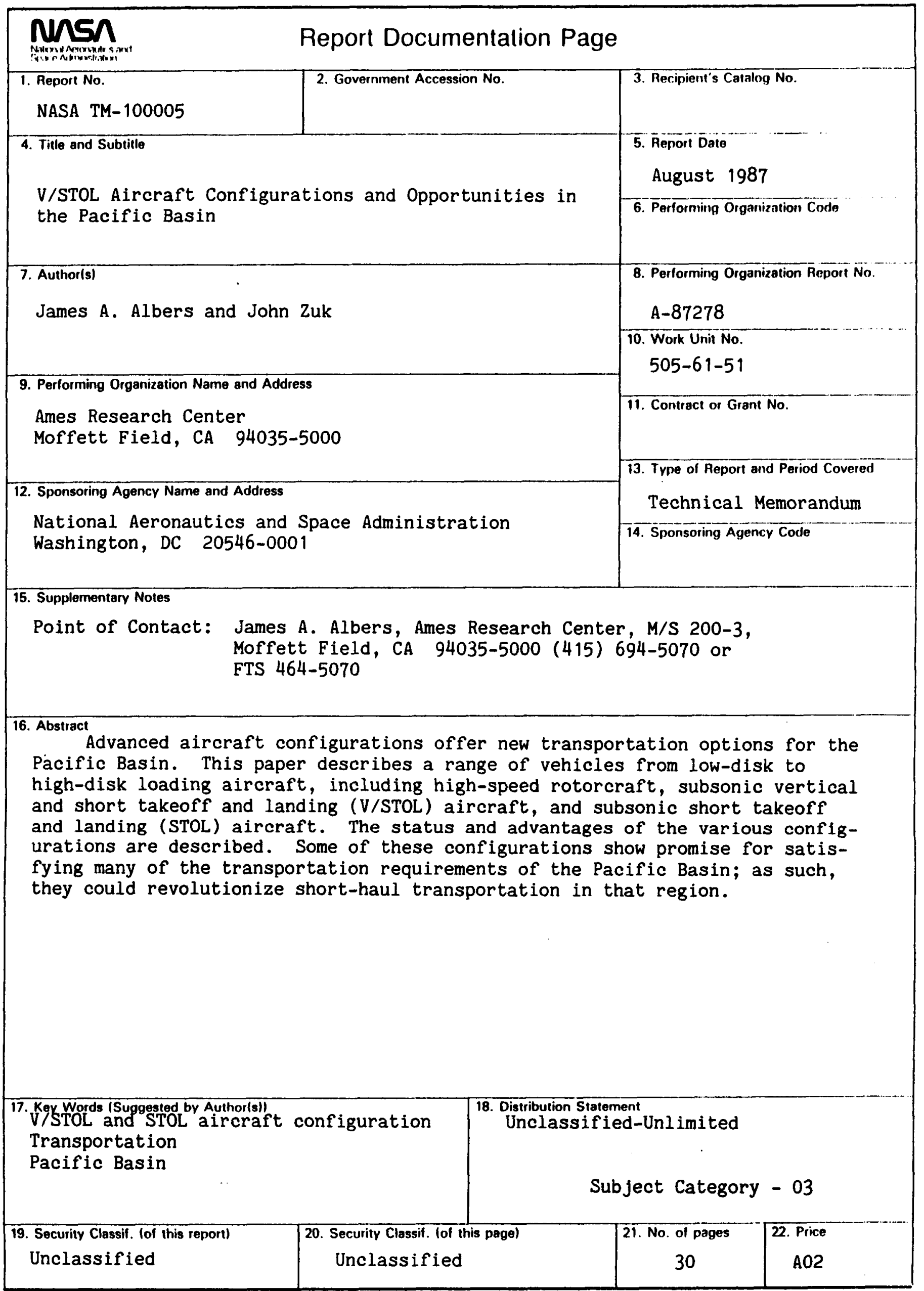

